\title{
Aggregate Implications of Changing Sectoral Trends
}

\author{
Andrew Foerster \\ Federal Reserve Bank of San Francisco \\ Andreas Hornstein \\ Federal Reserve Bank of Richmond \\ Pierre-Daniel Sarte \\ Federal Reserve Bank of Richmond \\ Mark Watson \\ Princeton University and NBER
}

January 2022

Working Paper 2019-16

https://www.frbsf.org/economic-research/publications/working-papers/2019/16/

\section{Suggested citation:}

Foerster, Andrew, Andreas Hornstein, Pierre-Daniel Sarte, and Mark Watson. 2022. "Aggregate Implications of Changing Sectoral Trends," Federal Reserve Bank of San Francisco Working Paper 2019-16. https://doi.org/10.24148/wp2019-16

The views in this paper are solely the responsibility of the authors and should not be interpreted as reflecting the views of the Federal Reserve Bank of San Francisco or the Board of Governors of the Federal Reserve System. 


\title{
Aggregate Implications of Changing Sectoral Trends*
}

\author{
Andrew T. Foerster \\ Federal Reserve Bank of San Francisco
}

Pierre-Daniel G. Sarte

Federal Reserve Bank of Richmond

\author{
Andreas Hornstein \\ Federal Reserve Bank of Richmond \\ Mark W. Watson \\ Princeton University and NBER
}

January 20, 2022

\begin{abstract}
We find disparate trend variations in TFP and labor growth across major U.S. production sectors and study their implications for the post-war secular decline in GDP growth. We describe how capital accumulation and the network structure of U.S. production interact to amplify the effects of sectoral trend growth rates in TFP and labor on trend GDP growth. We derive expressions that conveniently summarize this long-run amplification effect by way of sectoral multipliers. These multipliers are quantitatively large and for some sectors exceed three times their value added shares. We estimate that sector-specific factors have historically accounted for approximately 3/4 of long-run changes in GDP growth, leaving common or aggregate factors to explain only $1 / 4$ of those changes. Trend GDP growth fell by nearly 3 percentage points over the post-war period with the Construction sector alone contributing roughly 1 percentage point of that decline between 1950 and 1980. Idiosyncratic changes to trend growth in the Durable Goods sector then contributed an almost 2 percentage point decline in trend GDP growth between 2000 and 2018. Remarkably, no sector has contributed any steady significant increase to the trend growth rate of GDP in the past 70 years.
\end{abstract}

Keywords: trend growth, sectoral linkages, investment network, growth accounting JEL Codes: C32, E23, O41

${ }^{*}$ The views expressed herein are those of the authors and do not necessarily represent the views of the Federal Reserve Banks of San Francisco, Richmond, or the Federal Reserve System. We thank Jon Samuels of the Bureau of Economic Analysis for advice on the data, as well as Bill Dupor, Ivan Petrella, the editor, and four anonymous referees for thoughtful discussions and suggestions. We also thank John Fernald, Xavier Gabaix, Chad Jones, and participants at various university seminars and conferences for their comments. Daniel Ober-Reynolds, Eric LaRose, James Lee, and Lily Seitelman provided outstanding research assistance. Andrew Foerster: andrew.foerster@sf.frb.org, Andreas Hornstein: andreas.hornstein@rich.frb.org, PierreDaniel Sarte: pierre.sarte@rich.frb.org, Mark Watson: mwatson@princeton.edu. 


\section{Introduction}

Following the so-called Great Recession of 2008-2009, U.S. GDP recovered only very gradually resulting in a low average growth rate in the ensuing decade. Fernald, Hall, Stock, and Watson (2017) found that this weak recovery stemmed mainly from slow growth in total factor productivity (TFP) and a fall in labor input, and note that these adverse forces preceded the Great Recession. Antolin-Diaz, Drechsel, and Petrella (2017) likewise document a slowdown in output growth that predates the Great Recession. ${ }^{1}$ This paper studies what has in fact been a steady decline in trend GDP growth over the entire post-war period, 1950 - 2018. We explore the implications of TFP and labor input in accounting for this secular decline but we do so at a disaggregated sectoral level. We document disparate trend variations in TFP and labor growth across sectors and estimate the extent to which these trends are driven by idiosyncratic rather than common factors. We then study the implications of our empirical findings for trend growth within a multi-sector framework with linkages that mimic those of the U.S. economy including, crucially, in the production of investment goods.

We first document that common trend factors play a relatively small role in explaining sectoral trends in labor and TFP growth. For example, in Durable Goods, only 3 percent of the overall trend variation in labor and TFP growth is explained by their respective common trend factors. These findings, therefore, highlight the quantitative importance of idiosyncratic forces not only for business cycle fluctuations (see Gabaix (2011), Foerster, Sarte, and Watson (2011), and Atalay (2017)), but also for variations in trends. There are, however, exceptions in that in some service sectors, the trend variation in labor is explained to a greater degree by the common trend factor. Common trends explain a higher fraction of aggregate trend variation in labor and TFP growth because aggregation reduces the importance of sector-specific trends. We estimate that approximately $1 / 3$ of the variation in the trend growth rate of aggregate TFP is common across sectors while roughly $2 / 3$ is common for labor. One cannot, however, infer from these findings the role that common and sectoral growth trends in labor and TFP play in the overall trend growth rate of GDP. The reason is that capital accumulation and the network structure of U.S. production play a key role in translating those trends to the aggregate economy.

To explore the historical implications of changing sectoral trends for the long-run evolution of GDP growth, we derive balanced growth accounting equations in a dynamic multi-sector framework where sectors use not only materials but also investment goods produced in other sectors. We then use these new growth accounting equations to assess the aggregate effects of observed sectoral changes in the trend growth rates of labor and TFP. Our analysis, therefore, generalizes the work of Greenwood, Hercowitz, and Krusell (1997) on investment-specific technical change (ISTC) to an environment with multiple investment and intermediate

\footnotetext{
${ }^{1}$ Cette, Fernald, and Mojon (2016) suggest that a slowdown in productivity growth that began prior to the Great Recession reflects in part the fading gains from the Information Technology (IT) revolution. This view is consistent with the long lags associated with the productivity effects of IT adoption found by Basu et al. (2004), and the collapse of the dot-com boom in the early 2000s. Decker, Haltiwanger, Jarmin, and Miranda (2016) point to a decline in business dynamism that began in the 1980 s as an additional force underlying slowing economic activity.
} 
goods sectors that are interconnected in production. ${ }^{2}$ At the same time, our focus on estimating common and idiosyncratic sources of sectoral trends, and what their long-run aggregate implications are, differs from the literature building on Greenwood et al. (1997). Specifically, Fisher (2006), Justiniano, Primiceri, and Tambalotti (2010, 2011) and Basu, Fernald, Fisher, and Kimball (2013) are primarily concerned with the business cycle implications of sectoral shocks and, in particular, investment-specific shocks. More recently, vom Lehn and Winberry (2022) show that the input-output network of investment goods is critical in accounting for shifts in the cyclicality and relative volatilites of aggregate time series since the 1980s. ${ }^{3}$

We show that capital accumulation together with the network structure of U.S. production markedly amplifies the aggregate long-run growth effects of sectoral changes in the trend growth rates of TFP and labor. This amplification mechanism can be conveniently summarized in the form of sectoral multipliers that reflect the knock-on effects of production linkages. Given observed U.S. production linkages, the influence of individual sectors on GDP growth may be as large as 3 times their share in the economy including in Durable Goods, Construction, and Professional and Business Services.

Combining our empirical findings with the amplification effects of sectoral multipliers, we find that sector-specific trends have accounted for roughly $3 / 4$ of the trend variation in GDP growth over the postwar period, leaving aggregate or common factors to explain only $1 / 4$ of those changes. The secular decline in U.S. GDP growth since 1950, therefore, is a phenomenon largely driven by idiosyncratic rather than aggregate forces. These findings arise in part because of the knock-on effects of production linkages but also because sector-specific changes in TFP and labor have been historically large in some sectors. Thus, U.S. trend GDP growth fell by nearly 3 percentage points between 1950 and 2018. The combination of large trend TFP growth variations in the Construction sector along with its large sectoral multiplier means that it contributed roughly 1 percentage point of that decline between 1950 and 1980. The Durable Goods sector, after contributing significantly to an economic expansion in the 1990's, then contributed another 2 percentage point decline in trend GDP growth between 2000 and 2018. While Professional and Business Services stands out as having the second largest sectoral multiplier, smaller trend TFP growth variations in that sector imply that its contributions to the secular decline in GDP growth have been more muted to this point. Remarkably, no sector has contributed any steady significant increase to the trend growth rate of GDP over the post-war period.

Our paper also falls within the literature on equilibrium models with sectoral production networks first developed by Long and Plosser (1983) and later Horvath $(1998,2000)$ and Dupor (1999). Since then, a large

\footnotetext{
${ }^{2}$ Ngai and Pissarides (2007) provide a seminal study of balanced growth in a multi-sector environment. They consider both multiple intermediates and multiple capital-producing sectors but not at the same time. Importantly, their analysis abstracts from pairwise linkages in both intermediates and capital-producing sectors that play a key role in this paper. Ngai and Samaniego (2009) generalizes the model in Greenwood et al. (1997) to three sectors which allows for an input-output network in intermediate goods in carrying out growth accounting. Duarte and Restuccia (2020) include input-output linkages across sectors in a multi-sector environment abstracting from capital and study the implications of cross-country productivity differences in non-traditional service sectors.

${ }^{3}$ Basu et al. (2013) also construct a multi-sector extension of the Greenwood et al. (1997) environment, but they work with an aggregate capital stock and an aggregate labor endowment with each factor being perfectly mobile across sectors. In contrast to this paper, the authors study short-run responses to TFP shocks.
} 
body of work has explored important features of those models for generating aggregate fluctuations from idiosyncratic shocks. We maintain the original assumptions of competitive input and product markets as well as constant-returns-to-scale technologies. Even absent non-log-linearities in production emphasized by Baqaee and Farhi (2019), for example, and beyond the role of idiosyncratic shocks in explaining aggregate cyclical variations, the analysis reveals that sector-specific changes also dominate long-run variations in U.S. GDP growth. ${ }^{4}$

This paper is organized as follows. Section 2 gives an overview of the behavior of trend GDP growth over the past 70 years. Section 3 provides an empirical description of the trend growth rates of TFP and labor growth by industry and estimates the contributions of sector-specific and common factors to these trends. Section 4 develops the implications of these changes at the sector level in the context of a dynamic multi-sector model with production linkages in materials and investment. This model serves as the balanced growth accounting framework that we use to determine the aggregate implications of changes in the sectoral trend growth rates of labor and TFP. Section 5 presents our quantitative findings. Section 6 discusses salient implications of our work and outlines directions for future research. Section 7 concludes. A detailed online Technical Appendix contains a comprehensive description of the data, statistical methods, economic model, discussions of departures from our benchmark assumptions, and includes additional figures and tables referenced in the text.

\section{The Long-Run Decline in U.S. GDP Growth}

Figure 1 shows the behavior of U.S. GDP growth over the post-WWII period. Here, annual GDP growth is measured as the share-weighted value added growth from 16 sectors comprising the private U.S. economy; details are provided in the next section.

Panel A shows aggregate private-sector growth rates computed by chain-weighting the sectors, and by using three alternative sets of fixed sectoral shares computed as averages over the entire sample (1950-2018), over the first fifteen years of the sample (1950-1964), and over the final fifteen years (2004-2018). Panel A shows large variation in GDP growth rates - the standard deviation is 2.5 percent over the period 1950-2018 - but much of this variation is relatively short-lived and is associated with business cycles and other relatively transitory phenomena. Moreover, to the extent that sectoral shares have changed slowly over time, these share shifts have little effect in Panel A. In other words, changes in aggregate growth largely stem from changes within sectors rather than between them. Our interest, however, is in longer-run variation.

Panel B, therefore, plots centered 11-year moving averages of the annual growth rates. Here too there is variability. In the 1950s and early 1960s average annual growth exceeded 4 percent. Average growth fell to 3 percent in the 1970s, rebounded to nearly 4 percent in the 1990s, but plummeted to less than 2 percent

\footnotetext{
${ }^{4}$ See Gabaix (2011), Foerster, Sarte, and Watson (2011) and Atalay (2017) for assessments of the importance of idiosyncratic shocks in driving business cycle fluctuations. We introduce explicit dynamic considerations into the work of Acemoglu et al. (2012), Baqaee and Farhi (2019), and Miranda-Pinto (2019) combined with an empirical model that parses out common and idiosyncratic components of sectoral trend input growth.
} 
Figure 1: U.S. GDP Growth Rates 1950-2018

(percentage points at an annual rate)

(a) GDP Growth

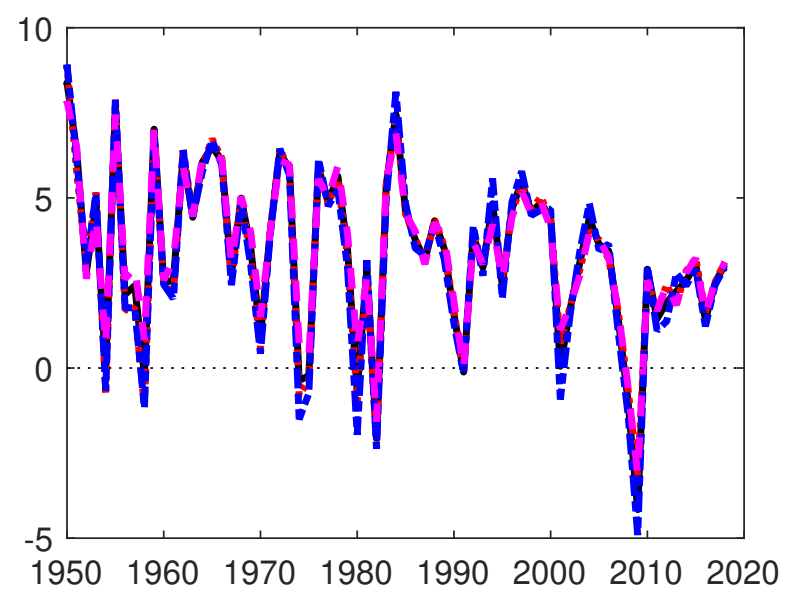

(c) Cyclically Adjusted GDP Growth

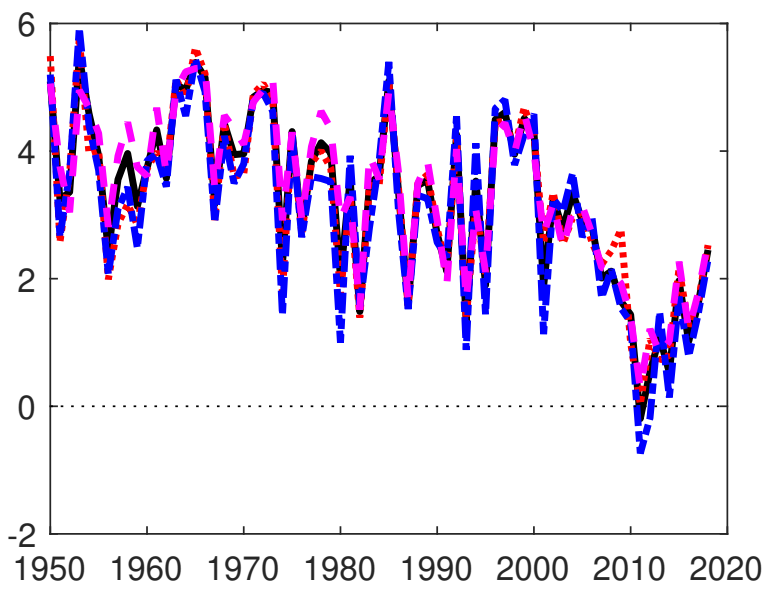

(b) GDP Growth

11-Year Centered Moving Average

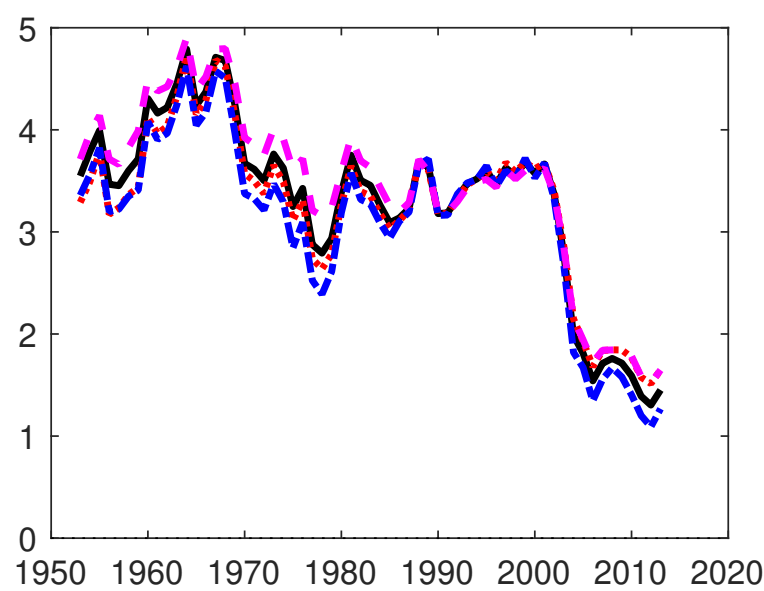

(d) Cyclically Adjusted GDP Growth 11-Year Centered Moving Average

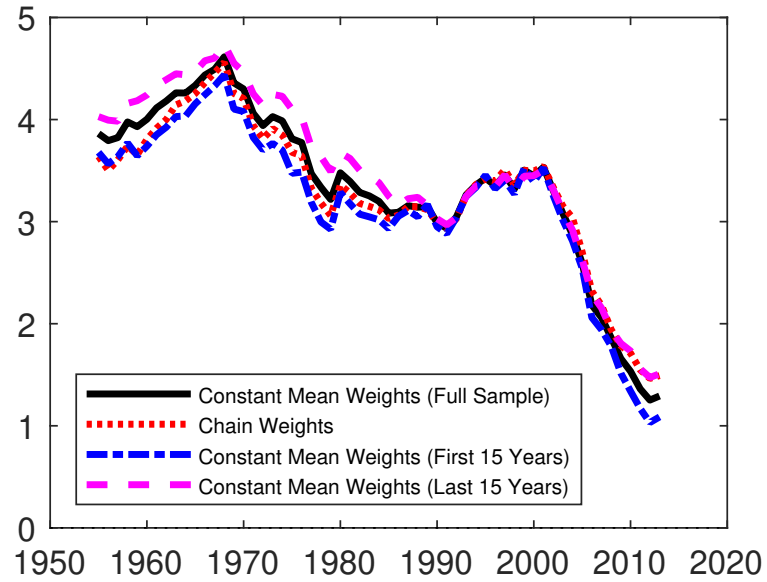

Notes: Growth rates are share-weighted value added growth rates from 16 sectors making up the private U.S. economy. Cyclical adjustment uses a regression on leads and lags of the first-difference in the unemployment rate.

in the 2000s (See Table 1). At these lower frequencies, the effects of slowly shifting shares over the sample become more visible, but still play a relatively minor role.

Panels C and D refine these calculations by eliminating the cyclical variation using an Okun's law regression as in Fernald et al. (2017). Thus, panel C plots the residuals from a regression of GDP growth rates onto a short distributed lead and lag of changes in the unemployment rate $\left(\Delta u_{t+1}, \Delta u_{t}, \Delta u_{t-1}\right)$. This cyclical adjustment eliminates much of the cyclical variability evident in panel A. In addition, the 11-year moving average in Panel D now produces a more focused picture of the trend variation in the growth rate of 
Table 1: Average GDP Growth Rates

\begin{tabular}{|c|c|c|c|c|c|c|c|c|}
\hline & $\begin{array}{r}\text { Const } \mathrm{N} \\
\text { Ful }\end{array}$ & $\begin{array}{l}\text { n Weights } \\
\text { ample }\end{array}$ & $\begin{array}{r}\text { Time- } \\
\text { We }\end{array}$ & $\begin{array}{l}\text { arying } \\
\text { hts }\end{array}$ & $\begin{array}{r}\text { Const } \mathrm{M} \\
\text { First }\end{array}$ & $\begin{array}{l}\text { n Weights } \\
\text { Years }\end{array}$ & $\begin{array}{r}\text { Const } \mathrm{M} \\
\text { Last }\end{array}$ & $\begin{array}{l}\text { n Weights } \\
\text { Years }\end{array}$ \\
\hline Dates & $\begin{array}{c}\text { Growth } \\
\text { rates }\end{array}$ & $\begin{array}{c}\text { Cyc-adj } \\
\text { rates }\end{array}$ & $\begin{array}{c}\text { Growth } \\
\text { rates }\end{array}$ & $\begin{array}{c}\text { Cyc-adj } \\
\text { rates }\end{array}$ & $\begin{array}{c}\text { Growth } \\
\text { rates }\end{array}$ & $\begin{array}{c}\text { Cyc-adj } \\
\text { rates }\end{array}$ & $\begin{array}{c}\text { Growth } \\
\text { rates }\end{array}$ & $\begin{array}{c}\text { Cyc-adj } \\
\text { rates }\end{array}$ \\
\hline $1950-2018$ & 3.3 & 3.2 & 3.3 & 3.2 & 3.2 & 3.1 & 3.4 & 3.4 \\
\hline 1950-1966 & 4.5 & 4.2 & 4.3 & 4.0 & 4.3 & 4.0 & 4.6 & 4.3 \\
\hline 1967-1983 & 3.1 & 3.6 & 3.0 & 3.5 & 2.8 & 3.4 & 3.4 & 3.9 \\
\hline 1984-2000 & 3.9 & 3.4 & 3.9 & 3.4 & 4.0 & 3.4 & 3.8 & 3.4 \\
\hline 2001-2018 & 1.9 & 1.8 & 2.0 & 2.0 & 1.7 & 1.7 & 2.0 & 2.0 \\
\hline
\end{tabular}

Notes: The values shown are averages of the series plotted in Figure 1 over the periods shown.

private GDP. Again, time-varying share weights have discernible but relatively small effect on the aggregate growth rate or its 11-year moving average.

The numbers reported in Table 1 frame the key question of this paper: why did the average growth rate of GDP fall from 4 percent per year in the 1950s to just over 3 percent in the 1980s and 1990s, and then further decline precipitously in the 2000s? As the different columns of the table make clear, this question arises regardless of the shares used in constructing GDP. We look to inputs - specifically TFP and labor at the sectoral level - for the answer. That is, interpreting long-run variations of the data as a time-varying balanced growth path, changes in trend GDP growth are in part determined by changes in the trend growth rates of those sectoral inputs. However, as the analysis in Section 4 makes clear, not all sectoral inputs are created equal. Sectors not only differ in their size, or their value-added share in GDP, but also in the share of materials or capital that they provide to other sectors.

Before investigating these input-output interactions, we begin by briefly describing the sectoral data and how sectoral value-added as well as labor and TFP inputs have evolved over the post-WWII period. In much of our analysis, we construct aggregates using constant weights computed using full-sample averages. As Figure 1 and Table 1 suggest, results using these constant shares are robust to alternative weighting schemes.

\section{An Empirical Description of Trend Growth in TFP and Labor}

As a first step, we estimate an empirical model of TFP and labor growth for different sectors of the U.S. economy. Our paper applies as a benchmark the insights of Hulten (1978) on the interpretation of aggregate total factor productivity (TFP) changes as a weighted average of sector-specific value-added TFP changes. In particular, under constant-returns-to-scale and perfect competition in product and input markets, the 
sectors' weights are the ratios of their valued added to GDP. ${ }^{5}$

We calculate standard TFP growth rates at the sectoral level, construct trend growth rates using a 'low-pass' filter, and estimate a statistical model to decompose these trend growth rates into common and sector-specific components.

\subsection{Data}

Sectoral TFP growth rates are calculated using KLEMS data from of the Bureau of Economic Analysis (BEA) and the Bureau of Labor Statistics (BLS) Integrated Industry-Level Production Accounts (ILPA). These data are attractive for our purposes because they provide a unified approach to the construction of gross output, the primary inputs capital and labor, as well as intermediate inputs ('materials') for a large number of industries. The KLEMS data are based on U.S. National Income and Product Accounts (NIPA) and consistently integrate industry data with input-output tables and Fixed Asset tables. The ILPA KLEMS data build on seminal work studying sectoral productivity accounting by Jorgenson and his collaborators and first summarized in Jorgenson et al. (1987).

Table 2 lists the 16 sectors we consider along with the growth rates of value added, labor, and TFP for each sector. Section 7 of the Technical Appendix provides a detailed discussion of the data and the construction of labor and TFP from quantity and price indices available in KLEMS. For each sector, the table shows average cyclically adjusted growth rates of value added, labor, and value added TFP over $1950-2018$, and it also shows their average shares in aggregate value added and labor input. The aggregate growth rates in the bottom row are the value-weighted averages of the sectoral growth rates with average value added and labor shares used as fixed weights.

Clearly sectors grow at different rates and this disparity is hidden in studies that only consider aggregates. Average real value added growth rates range from 1.4 percent in Mining to 4.9 percent in Information, bracketing the aggregate value added growth rate of 3.3 percent. With the exception of the Durable Goods sector, most sectors with growth rates that exceed the aggregate growth rate provide services. Similarly, labor input growth rates range from -1.3 percent in Agriculture to 3.5 percent in Professional and Business Services (PBS), bracketing the average aggregate growth rate of 1.6 percent. Again, most sectors with labor input growth rates that exceed the aggregate growth rate provide services. Finally, TFP growth rates range from -0.4 percent in Utilities to 3.1 percent in Agriculture, bracketing the average aggregate TFP growth rate of 0.8 percent. Sectoral TFP growth rates are less aligned with either value added or labor input growth rates. There are four sectors with TFP declines, namely Utilities, Construction, FIRE (x-Housing), and Education and Health, as well as a number of sectors with stagnant TFP levels. Negative TFP growth rates are a counter-intuitive but known feature of disaggregated industry data. These are in part attributed to

\footnotetext{
${ }^{5}$ In the absence of constant-returns-to-scale, perfect competition, or frictionless factor mobility, Basu and Fernald (1997, 2001) and Baqaee and Farhi (2018) show that aggregate TFP changes also incorporate reallocation effects. These effects reflect the movement of inputs between low and high return sectors in the absence of equalization of marginal rates of transformation and substitution.
} 
Table 2: 16 Sector Decomposition of the U.S. Private Economy (1950-2018)

\begin{tabular}{ll|ccc|cc}
\hline \hline \multicolumn{1}{c|}{ Sectors } & \multicolumn{3}{|c|}{$\begin{array}{c}\text { Average growth rate } \\
\text { Cyclically adjusted data } \\
\text { (Percentage points at an }\end{array}$} & $\begin{array}{c}\text { Average share } \\
\text { (Percentage points) }\end{array}$ \\
& & \multicolumn{3}{|c}{ annual rate) } & & \\
\hline & & Value & Labor & TFP & Value & Labor \\
& & Added & & & Added & \\
1 & Agriculture & 2.41 & -1.29 & 3.12 & 2.69 & 3.23 \\
2 & Mining & 1.38 & 0.37 & 0.39 & 2.11 & 1.55 \\
3 & Utilities & 2.09 & 1.00 & -0.42 & 2.37 & 1.04 \\
4 & Construction & 1.69 & 1.76 & -0.23 & 4.99 & 7.62 \\
5 & Durable Goods & 3.65 & 0.54 & 2.10 & 13.32 & 15.5 \\
6 & Nondurable Goods & 2.27 & 0.14 & 0.83 & 9.20 & 8.80 \\
7 & Wholesale Trade & 4.61 & 1.67 & 1.81 & 7.15 & 6.63 \\
8 & Retail Trade & 3.13 & 1.19 & 1.07 & 8.18 & 9.61 \\
9 & Trans. \& Ware. & 2.58 & 0.91 & 1.27 & 4.16 & 5.03 \\
10 & Information & 4.93 & 1.35 & 1.04 & 4.97 & 3.74 \\
11 & FIRE (x-Housing) & 3.88 & 2.77 & -0.03 & 9.97 & 7.53 \\
12 & PBS & 4.45 & 3.51 & 0.36 & 8.79 & 11.25 \\
13 & Educ. \& Health & 3.43 & 3.34 & -0.29 & 6.22 & 9.35 \\
14 & Arts, Ent., \& Food Svc. & 2.48 & 1.79 & 0.36 & 3.74 & 4.56 \\
15 & Other Services (x-Gov) & 1.99 & 0.52 & 1.04 & 2.94 & 4.37 \\
16 & Housing & 3.45 & 0.86 & 0.24 & 9.20 & 0.20 \\
& Aggregate & 3.32 & 1.55 & 0.82 & 100 & 100 \\
\hline
\end{tabular}

Notes: The values shown are average annual growth rates for the 16 sectors. The row labelled "Aggregate" is the constant share-weighted average of the 16 sectors.

measurement issues with respect to output, though land and the regulatory environment are also a factor in sectors such as Construction. ${ }^{6}$

To a first approximation, the contributions of the different sectors to aggregate outcomes are given by the nominal value added and labor input shares in the last two columns of Table 2. In those columns, two notable contributors to value added and TFP are Durable Goods and FIRE (x-Housing). The two largest contributors to labor payments are Durable Goods and Professional and Business Services. Over time, the shares of goods-producing sectors has declined while the shares of services-producing sectors has

\footnotetext{
${ }^{6}$ See for example Herkenhoff, Ohanian, and Prescott (2018).
} 
increased. However, despite these changes, aggregating sectoral outputs and inputs using constant mean shares, as opposed to time-varying shares, has little effect on the measurement of aggregate outputs and inputs (Figure 1).

\subsection{Empirical Framework}

The empirical analysis used to characterize the long-run properties of the data proceeds in 3 steps. First, we carry out a cyclical adjustment of sectoral TFP and labor raw growth rates to eliminate some of their cyclical variability. Second, we make use of methods discussed in Müller and Watson (2020) to extract smooth trends capturing the long-run evolution of the data. Finally, we carry out a factor analysis that quantifies the relative importance of common and sector-specific factors in driving these smooth trend components.

\subsubsection{Cyclical Adjustment}

Let $\Delta \widetilde{x}_{i, t}$ denote the growth rate $(100 \times$ the first difference of the logarithm $)$ of annual measurements of labor or TFP in sector $i$ at date $t$. These sectoral growth rates are volatile and, in many sectors, much of the variability is associated with the business cycle. Our interest is in trend (i.e., low-frequency) variation, which is more easily measured after cyclically adjusting the raw growth rates. Thus, as with the cyclically adjusted measure of GDP shown in Figure 1, we follow Fernald et al. (2017) and cyclically adjust these growth rates using the change in the unemployment rate, $\Delta u_{t}$, as a measure of cyclical resource utilization. That is, we estimate

$$
\Delta \widetilde{x}_{i, t}=\mu_{i}+\beta_{i}(L) \Delta u_{t}+e_{i, t},
$$

where $\beta_{i}(L)=\beta_{i, 1} L+\beta_{i, 0}+\beta_{i,-1} L^{-1}$ and the leads and lags of $\Delta u_{t}$ capture much of the business-cycle variability in the data. Throughout the remainder of the paper, we use $\Delta x_{i, t}=\Delta \widetilde{x}_{i, t}-\hat{\beta}_{i}(L) \Delta u_{t}$, where $\widehat{\beta}_{i}(L)$ denotes the OLS estimator, and where $x_{i, t}$ represents the implied cyclically adjusted value of sectoral TFP (denoted $z_{i, t}$ ) or labor input (denoted $\ell_{i, t}$ ) growth rates.

\subsubsection{Extracting Low-Frequency Trends}

We begin by extracting low-frequency trends from the data using a framework presented in Müller and Watson (2008). That framework is useful because on the one hand, it yields smooth trends that capture the long-run evolution of the growth rate of GDP and the associated growth rates of sectoral labor and TFP, and on the other hand, it simultaneously provides a convenient framework for statistical analysis. We give an overview below of the approach here. Müller and Watson (2020) provides a detailed Handbook discussion of statistical analysis using this framework. ${ }^{7}$

\footnotetext{
${ }^{7}$ The methods used are closely related to well-known spectral analysis methods using low-frequency Fourier transforms of the data. See Müller and Watson (2020) for a detailed discussion and references.
} 
Figure 2: Trend Rate of Growth of GDP

(percentage points at an annual rate)

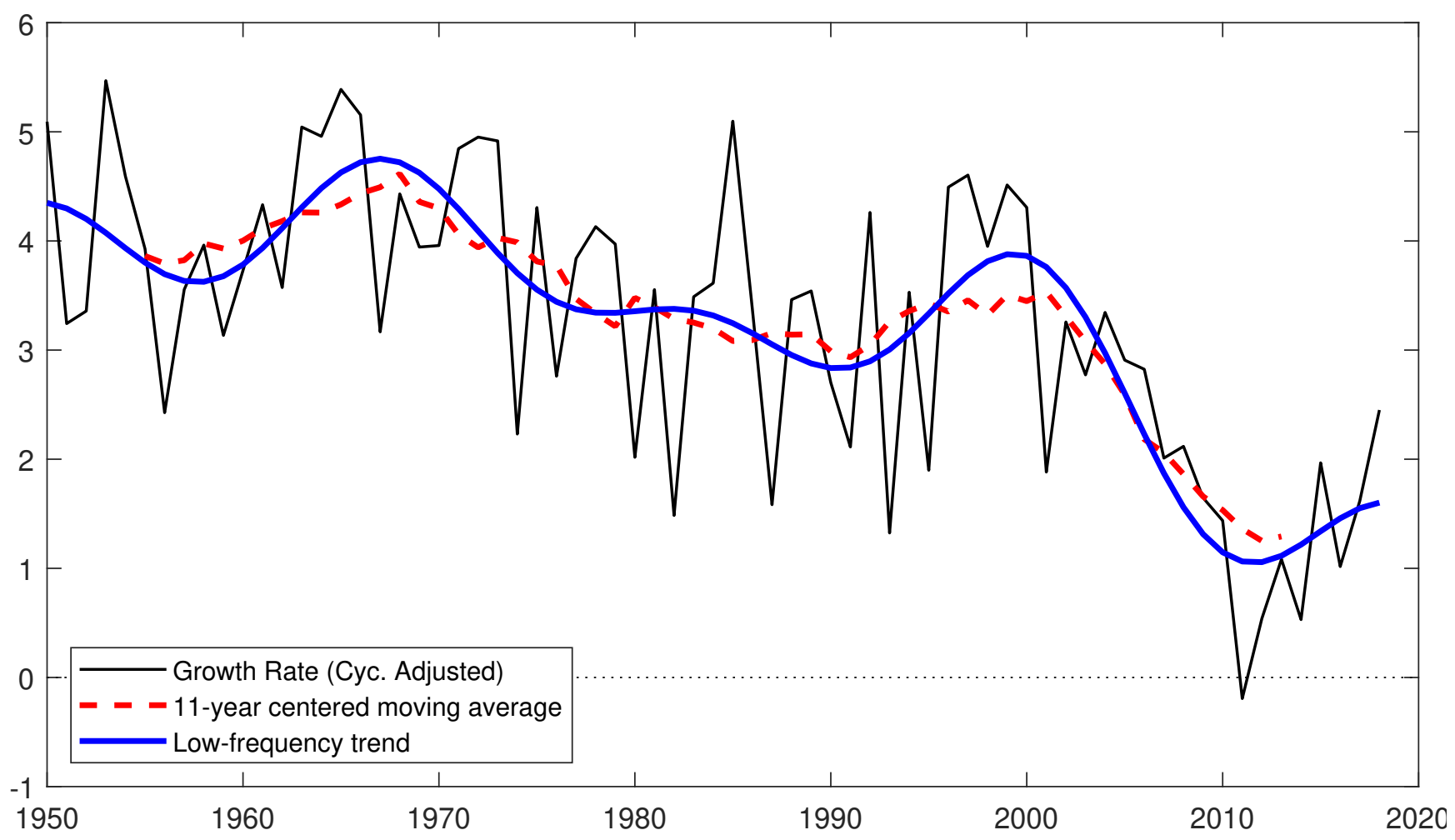

Notes: The low-frequency trend captures variability for periodicities longer than 17 years.

To extract low frequency trends in the growth rates of GDP, TFP and labor input, generically denoted by $\Delta x_{t}$, we regress these series onto a constant and a set of low-frequency periodic functions. In particular, let $\Psi_{j}(s)=\sqrt{2} \cos (j s \pi)$ denote a cosine function on $s \in[0,1]$ with period $2 / j$. The fitted values from the OLS regression of $\Delta x_{t}$ onto a constant and $\Psi_{j}((t-1 / 2) / T)$ for $j=1, \ldots, q$ and $t=1, \ldots, T$ capture the low-frequency variability in the sample corresponding to periodicities longer than $2 T / q$. Moreover, let $\Psi(s)$ denote the vector of regressors $\left[\Psi_{1}(s), \ldots, \Psi_{q}(s)\right]^{\prime}$ with periods 2 through $2 / q, \Psi_{T}$ the $T \times q$ matrix with $t^{t h}$ row $\boldsymbol{\Psi}((t-1 / 2) / T)^{\prime}$ and $\boldsymbol{\Psi}_{T}^{0}=\left[\mathbf{1}_{T}, \boldsymbol{\Psi}_{T}\right]$ where $\mathbf{1}_{T}$ is a $T \times 1$ vector of ones. The specific form used for the cosine weights implies that the columns of $\boldsymbol{\Psi}_{T}^{0}$ are orthogonal with $T^{-1} \boldsymbol{\Psi}_{T}^{0 /} \boldsymbol{\Psi}_{T}^{0}=I_{q+1}$. Thus, the OLS coefficients from the regression of $\Delta x_{t}$ onto $\mathbf{\Psi}_{T}^{0}$, that is $\left(\boldsymbol{\Psi}_{T}^{0 \prime} \mathbf{\Psi}_{T}^{0}\right)^{-1} \boldsymbol{\Psi}_{T}^{0 \prime} \Delta x_{1: T}$, amount to $q+1$ weighted averages of the data, $T^{-1} \boldsymbol{\Psi}_{T}^{0 \prime} \Delta x_{1: T}$, which we partition as $(\bar{x}, \mathbf{X})$ where $\bar{x}$ is the sample mean of $\Delta x_{t}$. In our application, $T=69$ so that with $q=8$, the regression captures long-run variation with periodicities longer than $17.25(=2 \times 69 / 8)$ years. These are the low-frequency growth rate trends analyzed in this paper. ${ }^{8}$

Figure 2 plots the growth rates of (cyclically-adjusted) GDP, its centered 11-year moving average, and

\footnotetext{
${ }^{8}$ Calculations presented in Müller and Watson (2008) show that these low-frequency projections approximate a low-pass filter for periods longer than $2 T / q$. That said, there is some leakage from higher frequencies and this makes the cyclical adjustment discussed above useful.
} 
Figure 3: Labor Growth Rates and Trends by Sector (percentage points at an annual rate)

Agriculture

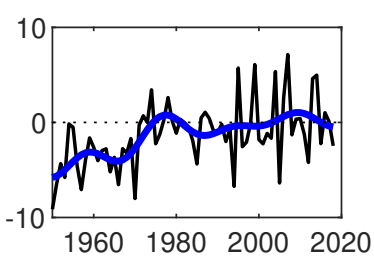

Durable Goods

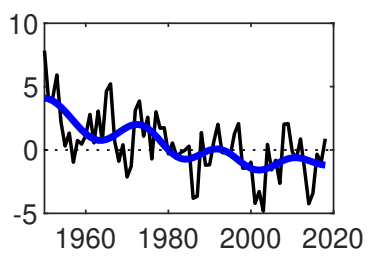

Trans. \& Ware.

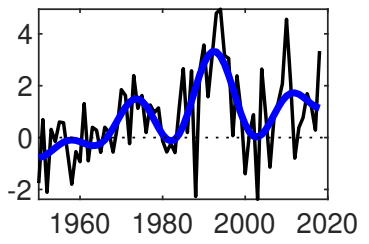

Educ. \& Health

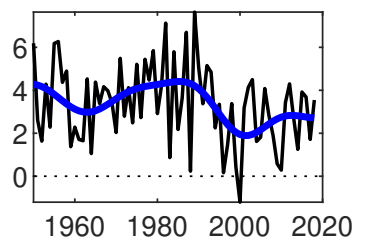

Mining

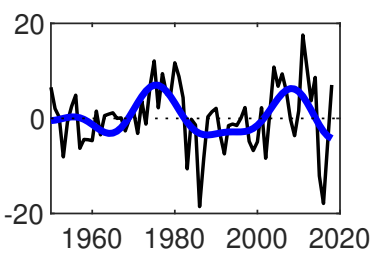

Nondurable Goods

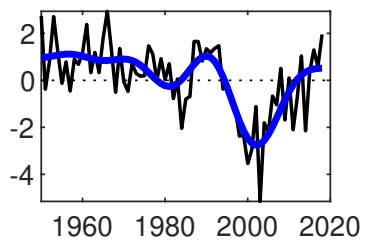

Information

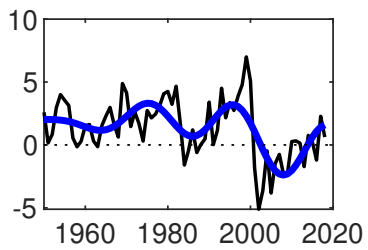

Arts, Ent. \& Food Svc.

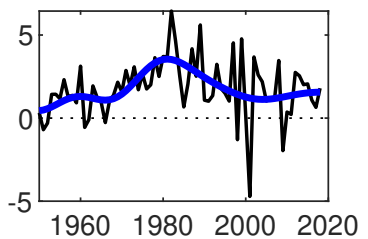

Utilities

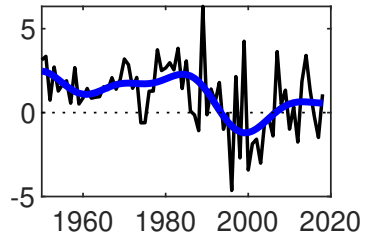

Wholesale Trade

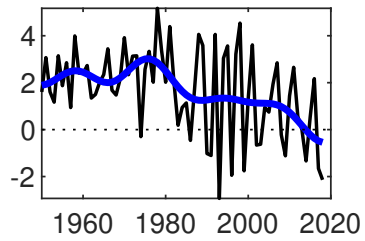

FIRE (x-Housing)

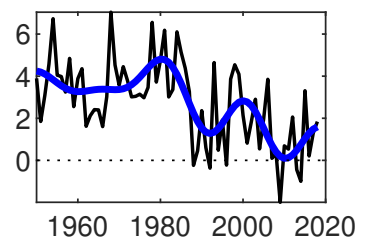

Other Services (x-Gov.)

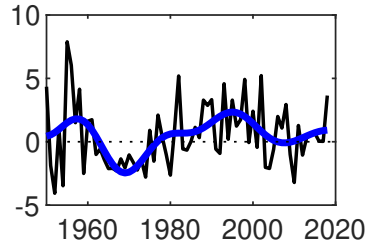

Construction

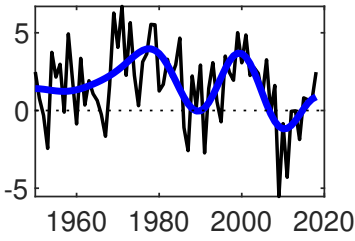

Retail Trade

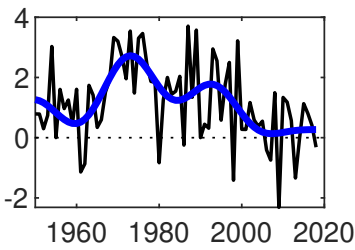

PBS

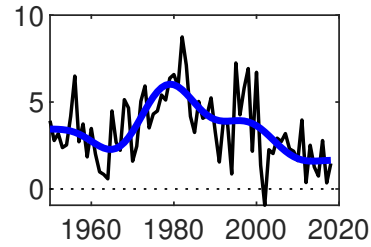

Housing

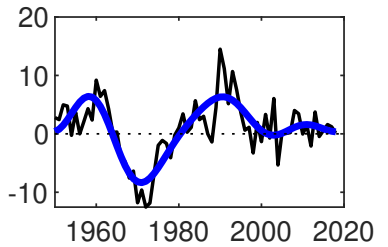

Notes: Each panel shows the cylically adjusted growth rate of labor for each sector in black, along with its lowfrequency trend in blue.

its trend computed as the fitted values from the low-frequency regression we have just described. ${ }^{9}$ The low-frequency trend smooths out the higher-frequency variation in the 11-year moving average. While the aggregate importance of sectoral shocks is known for business cycles - generally cycles with periods ranging from 2 to 8 years - our interest here is on the role of sectoral shocks for the aggregate trend variations shown in Figure 2. Thus, we will focus on cycles longer than 17 years as captured by the $\Psi$-weighted averages of the data.

Figures 3 and 4 plot the cyclically adjusted growth rates of labor and TFP for each of the 16 sectors

\footnotetext{
${ }^{9}$ An 11-year moving average is a crude low-pass filter with more than half of its spectral gain associated with periods longer than 17 years.
} 
Figure 4: TFP Growth Rates and Trends by Sector (percentage points at annual rate)

Agriculture

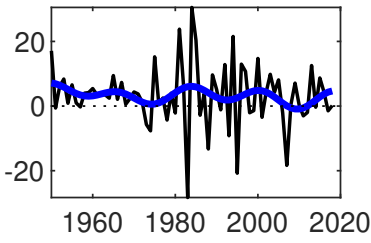

Durable Goods

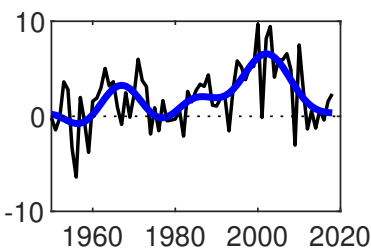

Trans. \& Ware.

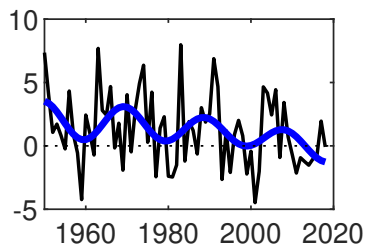

Educ. \& Health

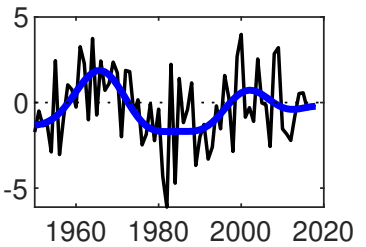

Mining

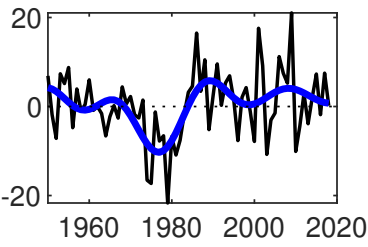

Nondurable Goods

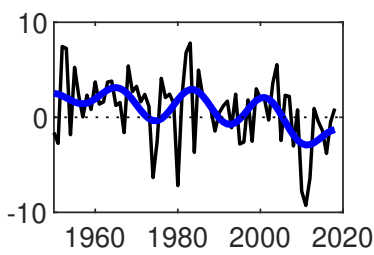

Information

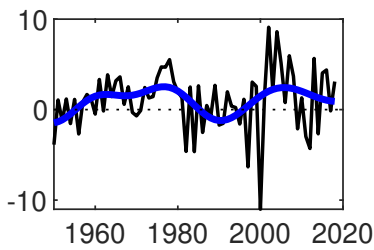

Arts, Ent. \& Food Svc.

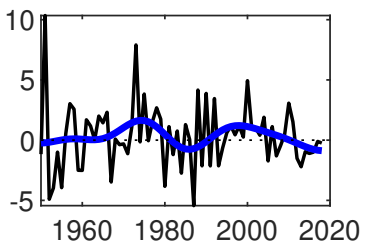

Utilities

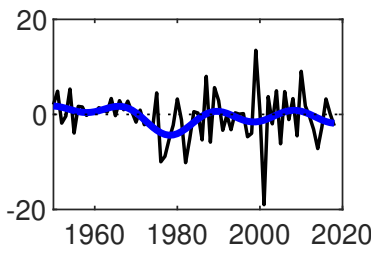

Wholesale Trade

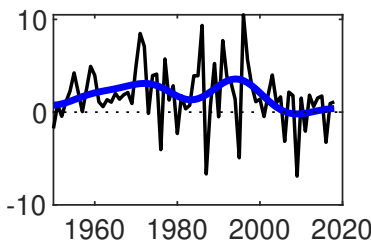

FIRE (x-Housing)

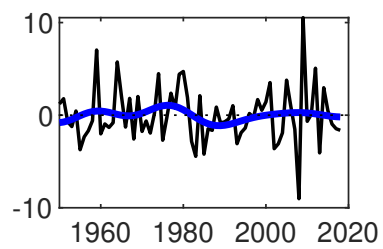

Other Services (x-Gov.)

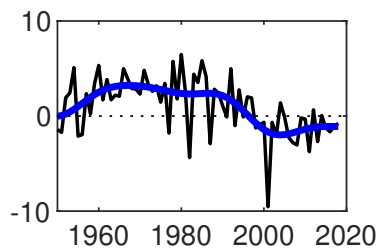

Construction

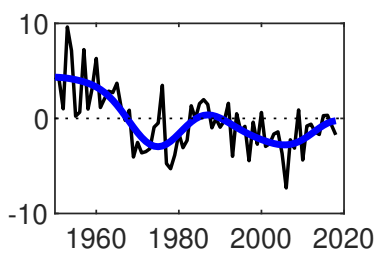

Retail Trade

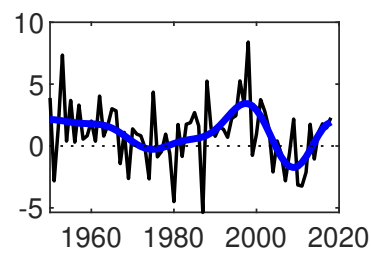

PBS

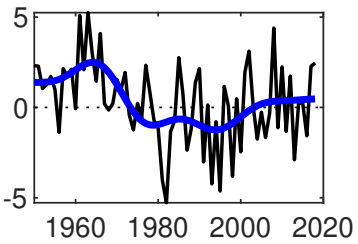

Housing

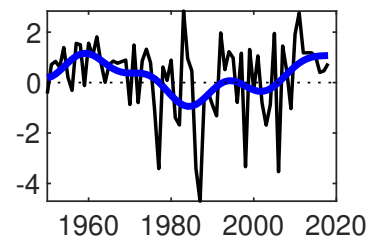

Notes: See notes for Figure 3.

along with their low frequency trends. The disparity in experiences across different sectors stands out. In particular, the trends show large variations across sectors and through time. For example, labor input was contracting at nearly 4 percent per year in Agriculture in the 1950s but stabilized near the end of the sample. In contrast, labor input in the Durables and Nondurable Goods sectors was increasing in the 1950s but has been contracting since the mid-1980s. At the same time, the trend growth rate of labor in several service sectors exhibit large ups and downs over the sample. Similar disparities are apparent in the sectoral growth rates of TFP. Trend TFP growth in Construction, for example, was around 5 percent in the 1950s, declined over the next couple of decades, and flattened out thereafter. In contrast, TFP trend growth in Durable Goods increased somewhat steadily from the 1950s to 2000 but has since collapsed by more than 5 
percentage points. In Sections 4 and 5, we quantify the aggregate implications of these sectoral variations in labor and TFP inputs.

\subsubsection{Decomposition of Trend Growth Rates into Common and Sector-Specific Factors}

To fix notation, let $g_{t}$ denote the trend growth rate constructed from our data on TFP or labor input, $\Delta x_{t}$. That is, $g_{t}$ is the fitted value from the OLS regression of $\Delta x_{t}$ onto a constant and the $q$ periodic functions $\Psi_{j}((t-1 / 2) / T)$, and is the low-frequency trend plotted in Figures 2-4. We saw earlier that because the regressors are mutually orthogonal, the OLS regression coefficients are $(\bar{x}, \mathbf{X})$ where $\bar{x}$ is the sample mean of $\Delta x_{t}$ and $\mathbf{X}$ is the $q \times 1$ vector of OLS regression coefficients from the regression of $\Delta x_{t}$ onto $\Psi_{j}((t-1 / 2) / T)$ for $j=1, \ldots, q$. Importantly, because the regressors are deterministic, the stochastic process for $g_{t}$ is completely characterized by the probability distribution of the $(q+1)$ random variables $(\bar{x}, \mathbf{X})$, and variation in $g_{t}$ over the sample is determined by the $q \times 1$ vector $\mathbf{X} .{ }^{10}$

A key implication of these results is that the original sample of $T$ observations on $\Delta x_{t}$ contains only $q$ pieces of independent information on the long-run properties of $\Delta x$. In our context, the $T=69$ annual observations contain only $q=8$ observations describing the long-run variation for periods longer than 17 years. This makes precise the intuition that a statistical analysis of long-run growth is inherently a "small sample' problem. Conveniently, however, this small sample problem involves variables that are averages of the $T$ observations - the elements of $\mathbf{X}$ - and that are, therefore, (approximately) normally distributed and readily analyzed using standard statistical methods.

Examination of the trends plotted in Figures 3 and 4 suggests that some of the trend variation may be common across sectors while some are sector-specific. In addition, in some sectors, trend variation in labor appears to be correlated with trend variation in TFP (and interestingly this correlation generally appears to be negative). We now outline an empirical model that captures these features.

Let $\Delta \ln \ell_{i, t}$ denote the rate of growth of labor input in sector $i$ in period $t$, and let $\Delta \ln z_{i, t}$ denote the rate of growth of TFP. Consider the factor model

$$
\left[\begin{array}{c}
\Delta \ln \ell_{i, t} \\
\Delta \ln z_{i, t}
\end{array}\right]=\left[\begin{array}{cc}
\lambda_{i}^{\ell} & 0 \\
0 & \lambda_{i}^{z}
\end{array}\right]\left[\begin{array}{c}
f_{t}^{\ell} \\
f_{t}^{z}
\end{array}\right]+\left[\begin{array}{c}
u_{i, t}^{\ell} \\
u_{i, t}^{z}
\end{array}\right]
$$

where $f_{t}=\left(f_{t}^{\ell} f_{t}^{z}\right)^{\prime}$ are unobserved common factors, $\lambda_{i}=\left(\lambda_{i}^{\ell} \lambda_{i}^{z}\right)^{\prime}$ are factor loadings, and $u_{i, t}=\left(u_{i, t}^{\ell} u_{i t}^{z}\right)^{\prime}$ are sector-specific disturbances. Denote the trend growth rates in $\left(\Delta \ln \ell_{i, t}, \Delta \ln z_{i, t}, f_{t}^{\ell}, f_{t}^{z}, u_{i, t}^{\ell}, u_{i, t}^{z}\right)$ by respectively $\left(g_{i, t}^{\ell}, g_{i, t}^{z}, g_{f, t}^{\ell}, g_{f, t}^{z}, g_{u, i, t}^{\ell}, g_{u, i, t}^{z}\right)$. Let $\mathbf{X}_{i}^{\ell}$ denote the $q \times 1$ vector of OLS coefficients associated with $\Psi_{j}((t-1 / 2) / T), j=1, \ldots, q$, in the regression of $\Delta \ln \ell_{i, t}$ on a constant and these periodic functions, and similarly for $\mathbf{X}_{i}^{z}, \mathbf{F}^{\ell}, \mathbf{F}^{z}, \mathbf{U}_{i}^{\ell}$ and $\mathbf{U}_{i}^{z}$. Pre-multiplying each element in equation (1) by $T^{-1} \psi_{t}^{\prime}$, where $T^{-1} \psi_{t}^{\prime}$

\footnotetext{
${ }^{10}$ By construction, the low frequency trends are highly serially correlated, and this needs to be accounted for in the statistical analysis. As it turns out, this is relatively straightforward given the framework described above. We highlight a few key features of this framework in Section 1 of the Technical Appendix and refer the reader to Müller and Watson (2020) and references therein for more detail.
} 
is the $t^{\text {th }}$ row of $\boldsymbol{\Psi}_{T}$, and summing, yields a factor decomposition of the trends and cosine transforms of the form (abstracting from the constant),

$$
\left[\begin{array}{l}
\mathbf{X}_{i}^{\ell} \\
\mathbf{X}_{i}^{z}
\end{array}\right]=\left[\begin{array}{cc}
\lambda_{i}^{\ell} I_{q} & 0 \\
0 & \lambda_{i}^{z} I_{q}
\end{array}\right]\left[\begin{array}{l}
\mathbf{F}^{\ell} \\
\mathbf{F}^{z}
\end{array}\right]+\left[\begin{array}{c}
\mathbf{U}_{i}^{\ell} \\
\mathbf{U}_{i}^{z}
\end{array}\right],
$$

which characterizes the low-frequency variation in the data. We estimate a version of (2) and use it to describe the common components, $\left(g_{f, t}^{\ell}, g_{f, t}^{z}\right)$, and sector-specific components, $\left(g_{u, i, t}^{\ell}, g_{u, i, t}^{z}\right)$, of the trend growth rates in sectoral labor input and TFP. ${ }^{11}$

The model is estimated using Bayes methods. While large-sample Bayes and Frequentist methods often coincide, the analysis of long-run trends is predicated on a small sample: in our application, the variation in each trend is characterized by only $q=8$ observations. Hence, large-sample frequentist results are irrelevant for our 'small-sample' empirical problem, and Bayes analysis will in general depend on the specifics of the chosen priors. Section 1 of the Technical Appendix contains details of the estimation method and empirical results for the low-frequency factor model. ${ }^{12}$

The priors we use are relatively uninformative except for the factor loadings. Let $\lambda^{\ell}=\left(\lambda_{1}^{\ell}, \ldots, \lambda_{16}^{\ell}\right)^{\prime}$ and note that the scale of $\lambda^{\ell}$ and $\mathbf{F}^{\ell}$ are not separately identified. Thus, we normalize $s_{\ell}^{\prime} \lambda^{\ell}=1$, where $s_{\ell}$ denotes the vector of average sectoral labor shares shown in Table 2. This imposes a normalization where the growth of aggregate labor, say $\Delta \ln \ell_{t}=\sum_{i=1} s_{\ell, i} \Delta \ln \ell_{i, t}$, satisfies $\Delta \ln \ell_{t}=f_{t}^{\ell}+\sum_{i} s_{\ell, i} u_{i, t}^{\ell}$. That is, a one unit change in $f^{\ell}$ corresponds to a unit change in the long-run growth rate of aggregate labor.

The prior for $\lambda^{\ell}$ is $\lambda^{\ell} \sim N\left(\mathbf{1}, \mathbf{P}_{\ell}\right)$ where $\mathbf{1}$ is a vector of 1 s and $\mathbf{P}_{\ell}=\eta^{2}\left(I_{16}-s_{\ell}\left(s_{\ell}^{\prime} s_{\ell}\right)^{-1} s_{\ell}^{\prime}\right)$ which enforces the constraint that $s_{\ell}^{\prime} \lambda^{\ell}=1$. The parameter $\eta$ governs how aggressively the estimates of $\lambda_{i}^{\ell}$ are shrunk toward their mean of unity. Our benchmark model uses $\eta=1$, so the prior puts approximately $2 / 3$ of its weight on values of $\lambda_{i}^{\ell}$ between 0 and 2 . Smaller values of $\eta$ tighten the constraint, making negative factor loadings less likely, while larger values of $\eta$ loosen it. To gauge the robustness of our conclusions to the choice of $\eta$, we will also show results with $\eta=1 / 2$ and $\eta=2$ in Section 5 . We use an analogous prior for $\lambda^{z}$.

\subsection{Estimated Sectoral and Aggregate Trend Growth Rates in Labor and TFP}

For our purposes, the key results are summarized in a table and three figures. The table summarizes salient features of the stochastic process describing the long-run evolution of the sectoral growth rates. The figures

\footnotetext{
${ }^{11}$ See Müller et al. (2020) for a related application studying long run growth and long horizons forecasts for per-capita GDP values of a panel of 113 countries. In equation (1), the common factors affect all sectors without leads and lags, an unrealistic assumption made for expositional purposes. The low-frequency model in (2) allows for lags in (1) that are short relative to the sample size. That said, lags of a decade or longer, such as those associated with general purpose technologies (e.g., semiconductors) will confound common and sector-specific sources of variation in the growth rates. See, for example, Basu et al. (2004)'s discussion of the diffusion of information and communications technology (ICT) and its delayed effects on productivity growth in ICT-using industries in the US and the UK.

${ }^{12}$ Frequentist methods for small-sample problems such as these are discussed, for example, in Müller and Watson (2008, 2016, 2018). As practical matter, these methods apply only to univariate and bivariate settings. Our application here involves 32 time series.
} 
Table 3: Changes in Trend Value of Labor and TFP Growth Rates

\begin{tabular}{|c|c|c|c|c|c|c|}
\hline & Sector & $\lambda^{\ell}$ & $\overline{\lambda^{z}}$ & $R_{\ell}^{2}$ & $R_{z}^{2}$ & $\operatorname{corr}(\ell, z)$ \\
\hline 1 & Agriculture & $\begin{array}{c}2.01 \\
(1.24,2.71)\end{array}$ & $\begin{array}{c}0.59 \\
(-0.59,1.64)\end{array}$ & $\begin{array}{c}0.21 \\
(0.06,0.44)\end{array}$ & $\begin{array}{c}0.02 \\
(0.00,0.13)\end{array}$ & $\begin{array}{c}-0.32 \\
(-0.52,-0.15)\end{array}$ \\
\hline 2 & Mining & $\begin{array}{c}0.73 \\
(-0.17,1.64)\end{array}$ & $\begin{array}{c}1.10 \\
(0.10,2.09)\end{array}$ & $\begin{array}{c}0.01 \\
(0.00,0.07)\end{array}$ & $\begin{array}{c}0.01 \\
(0.00,0.04)\end{array}$ & $\begin{array}{c}-0.35 \\
(-0.63,-0.06)\end{array}$ \\
\hline 3 & Utilities & $\begin{array}{c}1.13 \\
(0.41,1.82)\end{array}$ & $\begin{array}{c}1.36 \\
(0.36,2.35)\end{array}$ & $\begin{array}{c}0.24 \\
(0.04,0.58)\end{array}$ & $\begin{array}{c}0.05 \\
(0.00,0.29)\end{array}$ & $\begin{array}{c}0.22 \\
(-0.06,0.58)\end{array}$ \\
\hline 4 & Construction & $\begin{array}{c}1.55 \\
(0.95,2.08)\end{array}$ & $\begin{array}{c}1.26 \\
(0.21,2.66)\end{array}$ & $\begin{array}{c}0.33 \\
(0.10,0.61)\end{array}$ & $\begin{array}{c}0.02 \\
(0.00,0.19)\end{array}$ & $\begin{array}{c}-0.25 \\
(-0.55,-0.04)\end{array}$ \\
\hline 5 & Durable Goods & $\begin{array}{c}0.40 \\
(-0.23,1.03)\end{array}$ & $\begin{array}{c}1.31 \\
(0.44,2.17)\end{array}$ & $\begin{array}{c}0.03 \\
(0.00,0.18)\end{array}$ & $\begin{array}{c}0.03 \\
(0.00,0.15)\end{array}$ & $\begin{array}{c}-0.35 \\
(-0.63,-0.05)\end{array}$ \\
\hline 6 & Nondurable Goods & $\begin{array}{c}0.59 \\
(-0.20,1.38)\end{array}$ & $\begin{array}{c}1.22 \\
(0.36,2.13)\end{array}$ & $\begin{array}{c}0.06 \\
(0.01,0.29)\end{array}$ & $\begin{array}{c}0.04 \\
(0.00,0.23)\end{array}$ & $\begin{array}{c}-0.36 \\
(-0.65,-0.06)\end{array}$ \\
\hline 7 & Wholesale Trade & $\begin{array}{c}1.09 \\
(0.62,1.49)\end{array}$ & $\begin{array}{c}0.88 \\
(0.06,1.74)\end{array}$ & $\begin{array}{c}0.53 \\
(0.17,0.81)\end{array}$ & $\begin{array}{c}0.04 \\
(0.00,0.20)\end{array}$ & $\begin{array}{c}0.20 \\
(-0.06,0.53)\end{array}$ \\
\hline 8 & Retail Trade & $\begin{array}{c}0.80 \\
(0.26,1.29)\end{array}$ & $\begin{array}{c}1.14 \\
(0.17,2.82)\end{array}$ & $\begin{array}{c}0.26 \\
(0.04,0.60)\end{array}$ & $\begin{array}{c}0.05 \\
(0.00,0.85)\end{array}$ & $\begin{array}{c}0.06 \\
(-0.25,0.62)\end{array}$ \\
\hline 9 & Trans. \& Ware. & $\begin{array}{c}-0.04 \\
(-0.75,0.72)\end{array}$ & $\begin{array}{c}0.88 \\
(-0.02,1.79)\end{array}$ & $\begin{array}{c}0.05 \\
(0.00,0.23)\end{array}$ & $\begin{array}{c}0.06 \\
(0.00,0.28)\end{array}$ & $\begin{array}{c}0.06 \\
(-0.25,0.36)\end{array}$ \\
\hline 10 & Information & $\begin{array}{c}1.34 \\
(0.69,2.01)\end{array}$ & $\begin{array}{c}0.77 \\
(-0.18,1.81)\end{array}$ & $\begin{array}{c}0.22 \\
(0.04,0.51)\end{array}$ & $\begin{array}{c}0.03 \\
(0.00,0.19)\end{array}$ & $\begin{array}{c}-0.25 \\
(-0.56,-0.00)\end{array}$ \\
\hline 11 & FIRE (x-Hol & $\begin{array}{c}1.92 \\
(1.34,2.48)\end{array}$ & $\begin{array}{c}0.35 \\
(-0.42,1.34)\end{array}$ & $\begin{array}{c}0.76 \\
(0.35,0.92)\end{array}$ & $\begin{array}{c}0.08 \\
(0.01,0.40)\end{array}$ & $\begin{array}{c}0.01 \\
(-0.41,0.40)\end{array}$ \\
\hline 12 & PBS & $\begin{array}{c}1.87 \\
(1.48,2.29)\end{array}$ & $\begin{array}{c}0.90 \\
(-0.01,1.80)\end{array}$ & $\begin{array}{c}0.64 \\
(0.31,0.87)\end{array}$ & $\begin{array}{c}0.06 \\
(0.00,0.39)\end{array}$ & $\begin{array}{c}-0.92 \\
(-0.98,-0.67)\end{array}$ \\
\hline 13 & Educ. \& Health & $\begin{array}{c}0.59 \\
(-0.06,1.05)\end{array}$ & $\begin{array}{c}1.36 \\
(0.24,2.49)\end{array}$ & $\begin{array}{c}0.16 \\
(0.01,0.56)\end{array}$ & $\begin{array}{c}0.10 \\
(0.01,0.54)\end{array}$ & $\begin{array}{c}-0.63 \\
(-0.88,-0.26)\end{array}$ \\
\hline 14 & Arts, Ent., \& Food Svc. & $\begin{array}{c}1.19 \\
(0.69,1.75)\end{array}$ & $\begin{array}{c}0.37 \\
(-0.39,1.31)\end{array}$ & $\begin{array}{c}0.37 \\
(0.11,0.67)\end{array}$ & $\begin{array}{c}0.05 \\
(0.00,0.26)\end{array}$ & $\begin{array}{c}-0.18 \\
(-0.51,0.02)\end{array}$ \\
\hline 15 & Other Services (x-Gov) & $\begin{array}{c}0.68 \\
(-0.10,1.48)\end{array}$ & $\begin{array}{c}0.74 \\
(-0.10,1.63)\end{array}$ & $\begin{array}{c}0.06 \\
(0.01,0.23)\end{array}$ & $\begin{array}{c}0.02 \\
(0.00,0.10)\end{array}$ & $\begin{array}{c}-0.07 \\
(-0.35,0.17)\end{array}$ \\
\hline 16 & Housing & $\begin{array}{c}0.82 \\
(-0.13,1.74) \\
\end{array}$ & $\begin{array}{c}0.75 \\
(0.08,1.50) \\
\end{array}$ & $\begin{array}{c}0.01 \\
(0.00,0.04) \\
\end{array}$ & $\begin{array}{c}0.10 \\
(0.01,0.44) \\
\end{array}$ & $\begin{array}{c}0.07 \\
(-0.21,0.40) \\
\end{array}$ \\
\hline & Aggregate & 1.0 & 1.0 & $\begin{array}{c}0.67 \\
(0.48,0.82)\end{array}$ & $\begin{array}{c}0.30 \\
(0.10,0.58)\end{array}$ & $\begin{array}{c}-0.29 \\
(-0.72,-0.13)\end{array}$ \\
\hline
\end{tabular}

Notes: The estimates are posterior medians with 68 percent credible intervals shown parentheses. The entries under cor $(\ell, z)$ are the correlations between $g_{u, i, t}^{\ell}$ and $g_{u, i, t}^{z}$ for the rows corresponding to sectors, and correlations between $g_{f, t}^{\ell}$ and $g_{f, t}^{z}$ for the row labeled Aggregate.

summarize the historical evolution of the long-run growth rates over the sample period.

Table 3 reports the posterior medians for $\lambda$ along with 68 percent credible intervals. ${ }^{13}$ Also reported

\footnotetext{
${ }^{13}$ Throughout the paper, we report 68 equal-tail percent credible intervals. Section 1 of the Technical Appendix also reports
} 
Figure 5: Aggregate Trend Growth Rates in Labor and TFP: Common and Sector-Specific Components (percentage points at annual rate)

(a) Aggregate Labor

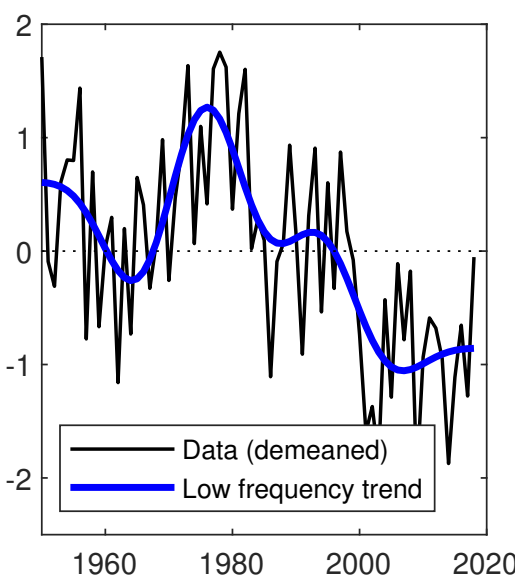

(d) Aggregate TFP

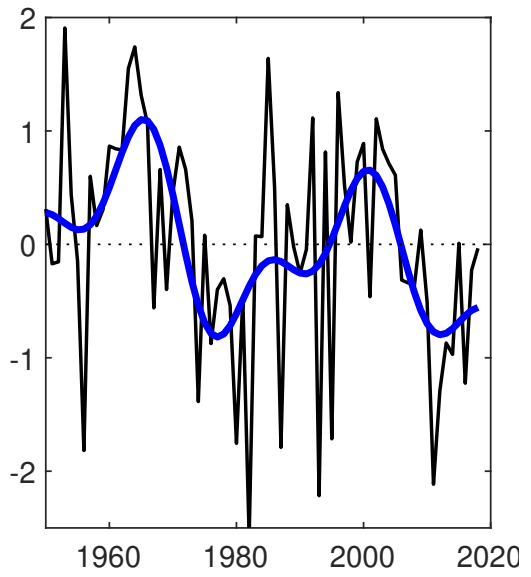

(b) Labor: Common

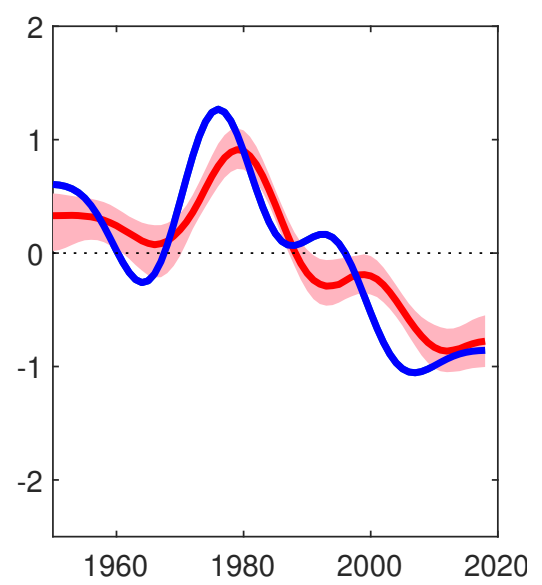

(e) TFP: Common

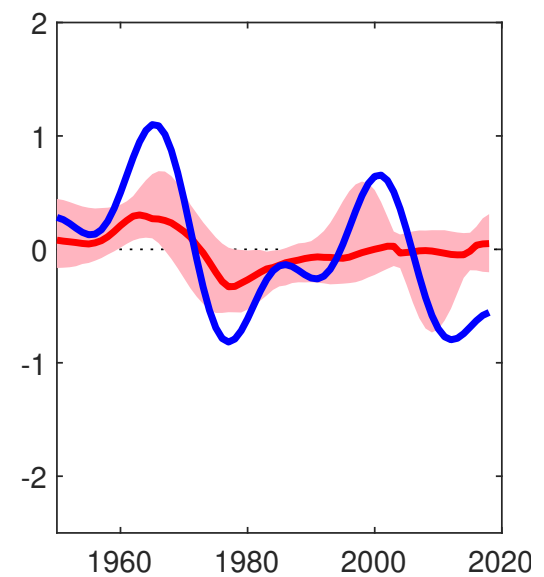

(c) Labor: Sector-Specific

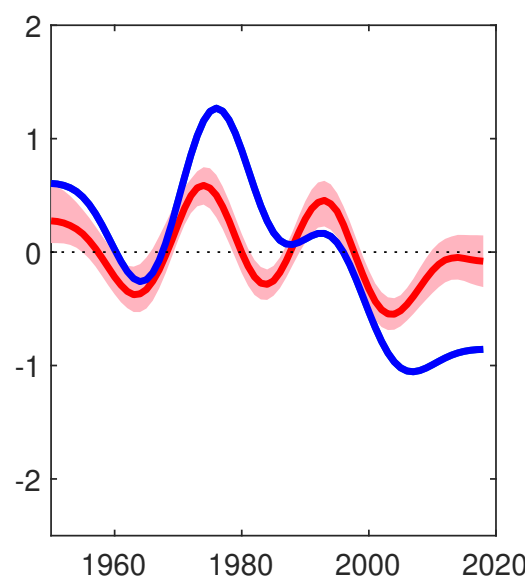

(f) TFP: Sector-Specific

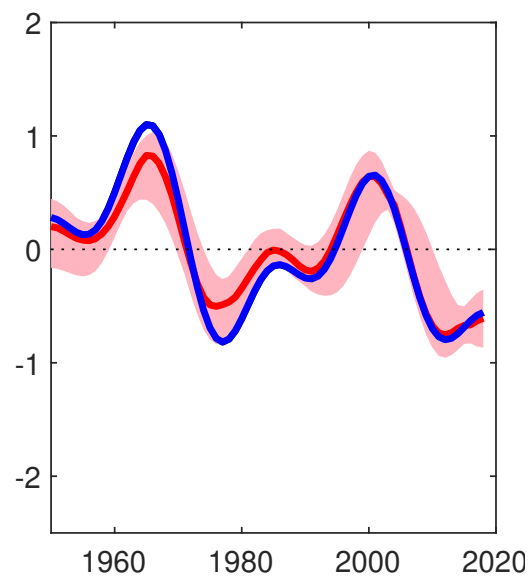

Notes: Panels (a) and (d) show the growth rates (deviated from their sample mean) and the low-frequency trend. The other panels show the low-frequency trend and its decomposition into common and sector-specific components. The red lines denote the posterior median and the shaded areas are (pointwise) equal-tail $68 \%$ credible intervals.

is the fraction of the trend variability in each sector explained by the common trend factors, $\left(g_{f, t}^{\ell}, g_{f, t}^{z}\right)$, which is denoted by $R_{\ell}^{2}$ and $R_{z}^{2}$ in the table. Finally, the table also reports the correlation between the sector-specific labor and TFP trends, $\left(g_{u, i, t}^{\ell}, g_{u, i, t}^{z}\right)$, in each sector and the correlation between the common trends $\left(g_{f, t}^{\ell}, g_{f, t}^{z}\right)$.

Looking first at the median values of the factor loadings, Agriculture, FIRE (x-Housing), and PBS have the largest factor loadings for labor, and Transportation and Warehousing, and Durable and Nondurable selected 90 percent credible intervals, which in some cases are markedly wider. We remind the reader that these long-run empirical results use only $q=8$ independent observations on labor input and TFP for each of the 16 sectors. 
Goods have the smallest. Utilities, Durable Goods and Construction have the largest loadings for TFP, while FIRE (x-Housing) and Arts, Entertainment, and Food Services have the smallest. The 68 percent credible intervals are relatively wide and give a quantitative sense of how information about the long-run is limited in our sample: the average width is 1.3 for $\lambda^{\ell}$ and 1.9 for $\lambda^{z}$. That said, for the majority of sectors, the posterior puts relatively little weight on negative values of the factor loadings. Detailed results for alternative priors are available in Section 1 of the Technical Appendix.

The sectoral $R^{2}$ values are typically low indicating that common trend factors play a relatively muted role in explaining overall sectoral trends. For example, in Durable Goods, only 3 percent of the overall trend variation in labor and TFP growth is explained by their respective common trend factors. Notable exceptions for $R_{\ell}^{2}$ arise in several service sectors, for example in FIRE (x-Housing) where 76 percent of the trend variation in labor is explained by the common trend factor. Interestingly, the posterior suggests that the sector-specific trends in labor and TFP are generally negatively correlated, rather dramatically so for Professional and Business Services.

The final row of the table shows the results for aggregate values of labor and TFP. By construction, the share-weighted factor loadings sum to unity. The common trends, $\left(g_{f, t}^{\ell}, g_{f, t}^{z}\right)$, are also negatively correlated. The $R^{2}$ values are higher for the aggregates because aggregation reduces the importance of the sector-specific trends. The point estimates suggest that roughly $2 / 3$ of the variation in the trend growth rate of labor is common across sectors while roughly $1 / 3$ is common for TFP. However, one cannot directly infer from these findings the role that common growth trends in labor and TFP play in the overall trend growth rate of GDP. The reason is production linkages across sectors. In particular, the effective weight that each sector has in the aggregate economy can differ considerably from its value added share in GDP. Thus, as we show below, sectors such as Durable Goods, Construction, and Professional and Business Services, with extensive linkages to other sectors as input suppliers, have an outsize influence on the aggregate trend.

Figure 5 shows a historical decomposition of the trends in aggregate labor and TFP growth rates arising from the common factors, $\left(g_{f}^{\ell}, g_{f}^{z}\right)$, and sector specific components, $\left\{g_{u, i}^{\ell}, g_{u, i}^{z}\right\}_{i=1}^{16}$. Panels (a) and (d) show the (demeaned) values of the aggregate growth rates with the associated low frequency trend. The other panels decompose the trend into its common (panels (b) and (e)) and sector-specific components (panels (c) and (f)). This decomposition relies on standard signal extraction formulas to compute the posterior distribution of $(\mathbf{F}, \mathbf{U})$ given $\mathbf{X}$, and the figure includes $68 \%$ (pointwise) credible intervals for the resulting common and sector-specific trends that incorporate uncertainty about the model's parameter values. Figure 5, panel (b), suggests that much of the increase in the trend growth rate of aggregate labor in the 1960s and 1970s, and subsequent decline in the 1980s and 1990s (both typically associated with demographics), are captured by the model's common factor in labor. Sector-specific labor factors, for the most part, played a supporting role. In contrast, while the model's aggregate common factor played a role in the decline of trend TFP growth the 1970s, the low frequency variation in the series since then has been associated almost exclusively with sector-specific sources.

Figures 6 and 7 present the trend growth rates for each of the sectors (shown previously in Figure 5) 
Figure 6: Labor Trends and Sector-Specific Components (percentage points at annual rate)

Agriculture

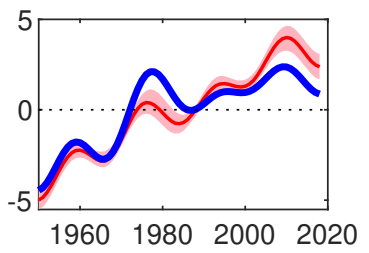

Durable Goods

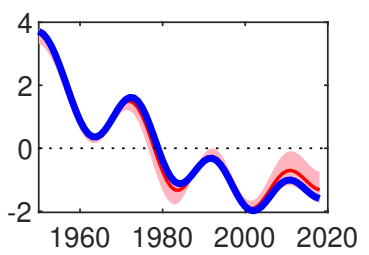

Trans. \& Ware.

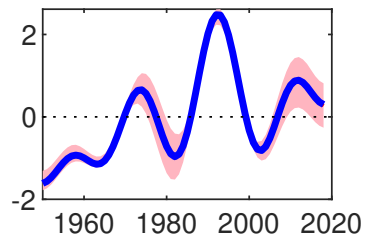

Educ. \& Health

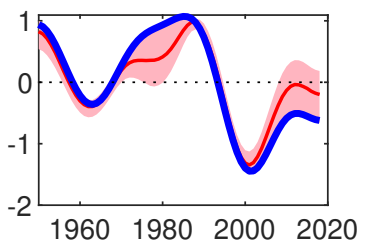

Mining

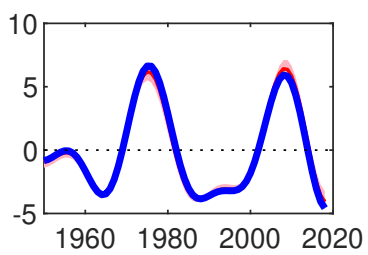

Nondurable Goods

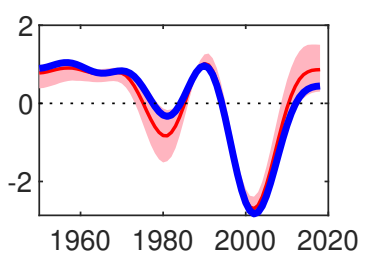

Information

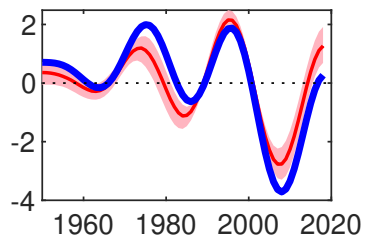

Arts, Ent. \& Food Svc.

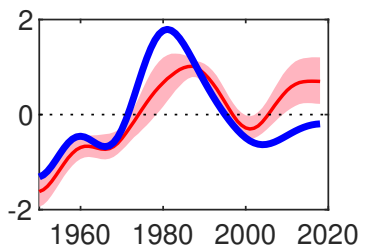

Utilities

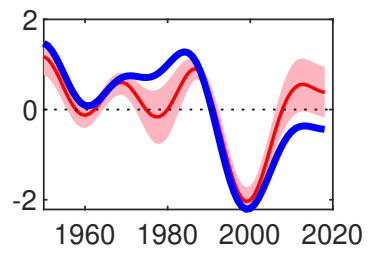

Wholesale Trade

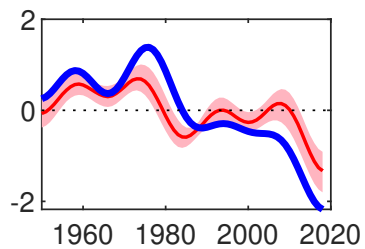

FIRE (x-Housing)

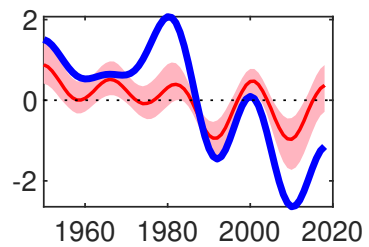

Other Services (x-Gov.)

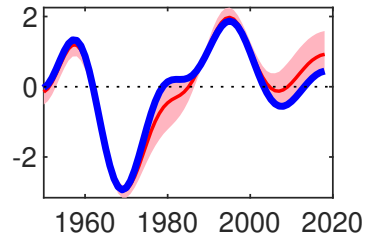

Construction

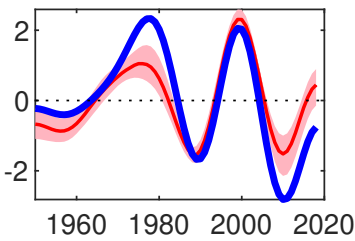

Retail Trade

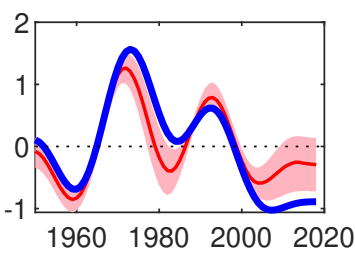

PBS

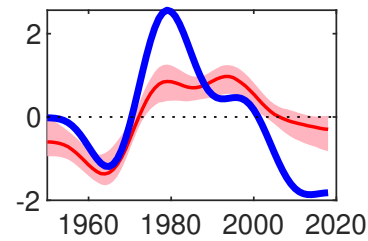

Housing

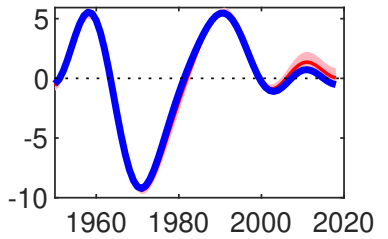

Notes: Each panel shows the low-frequency trend for sectoral growth rate (in blue) and its sector-specific component (in red). The red lines denote the posterior median and the shaded areas are (pointwise) equal-tail $68 \%$ credible intervals.

along with the estimated sector-specific $\left(g_{u, i, t}^{\ell}, g_{u, i, t}^{z}\right)$ components. Consistent with the $R^{2}$ values shown in Table 3, much of the variation in the trend growth rates of sectoral TFP and labor is associated with sectorspecific factors, and this is particularly true for TFP. Notable in Figures 6 and 7 is the negative correlation between the low frequency components of labor and TFP sectoral growth. ${ }^{14}$

\footnotetext{
${ }^{14}$ One explanation for this negative correlation relies on complementarities in preferences (see Ngai and Pissarides (2007), Herrendorf et al. (2013)). Technological progress in a sector leads to reduced spending on that sector's consumption goods and, by implication, reduced employment in that sector as well.
} 
Figure 7: TFP Trends and Sector-Specific Components (percentage points at annual rate)

Agriculture

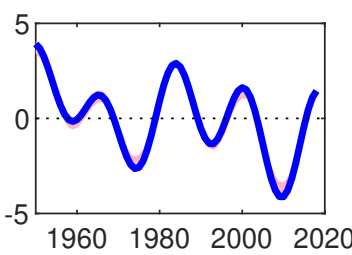

Durable Goods

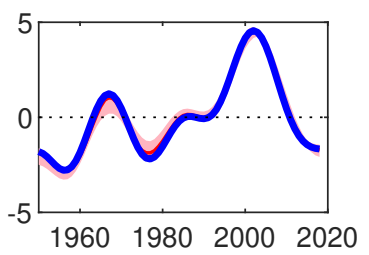

Trans. \& Ware.

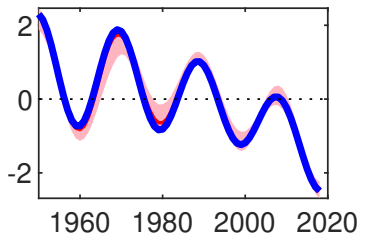

Educ. \& Health

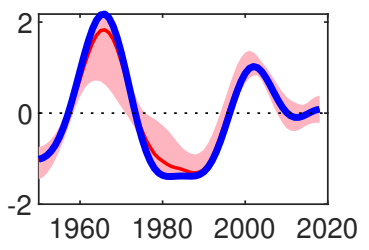

Mining

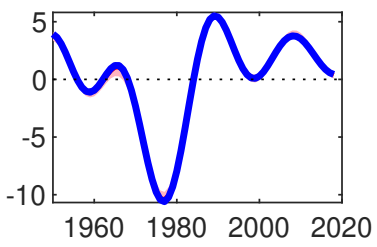

Nondurable Goods

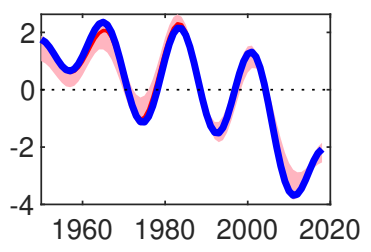

Information

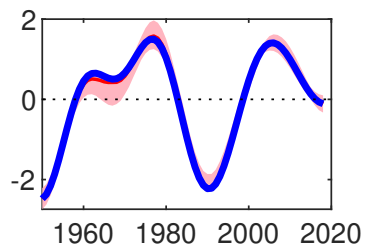

Arts, Ent. \& Food Svc.

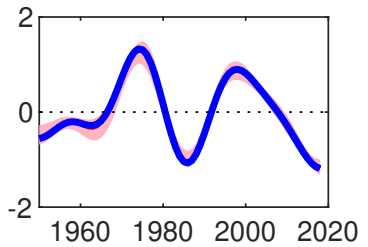

Utilities

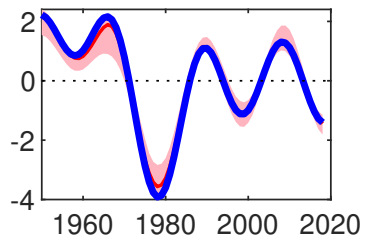

Wholesale Trade

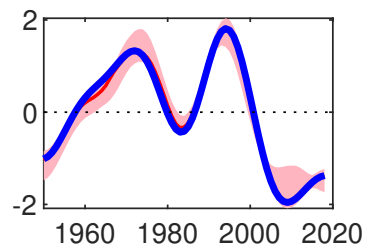

FIRE (x-Housing)

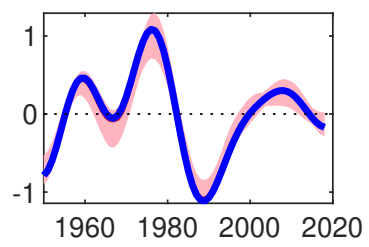

Other Services (x-Gov.)

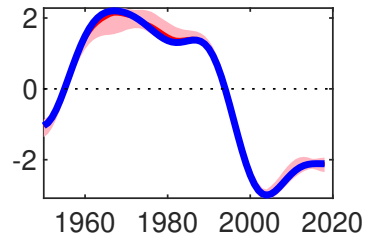

Construction

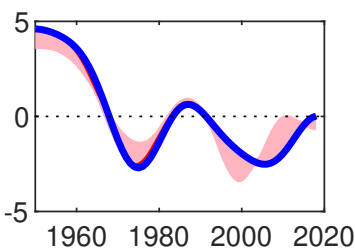

Retail Trade

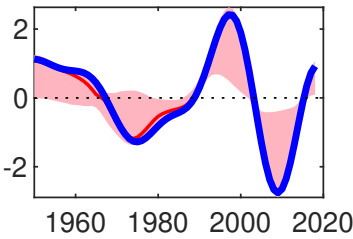

PBS

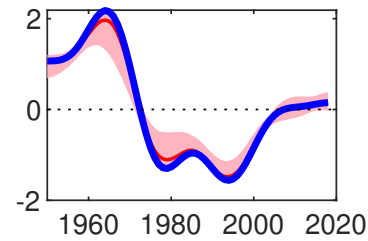

Housing

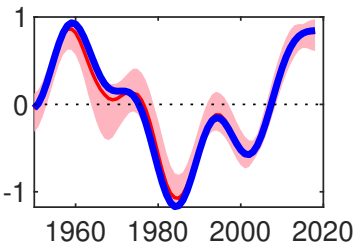

Notes: See notes to Figure 6 .

\section{Sectoral Trends and the Aggregate Economy}

Given the evolution of sectoral trend growth rates for labor and TFP over the past 70 years, this section explores their implications for long-run GDP growth. The key consideration here is that production sectors are linked because each sector uses capital goods and materials produced in other sectors. Therefore, we consider a multi-sector growth model that features these interactions. Consistent with our TFP calculations in Section 3, the model also features competitive product and input markets.

We consider a structural framework with preferences and technologies that are unit elastic so that the economy evolves along a balanced growth path in the long run. Capital accumulation interacts with 
production linkages to amplify the effects of sector-specific sources of growth. In particular, changes in the growth rate of labor or TFP in one sector affect not only its own value added growth but also that of all other sectors. We derive closed form expressions for the long-run multipliers summarizing the aggregate growth implications of these network effects for each sector. The magnitude of the multiplier associated with a given sector depends on its role and importance as a supplier of capital and materials to other sectors.

We first outline a general $n$-sector model that we use in our quantitative analysis. After introducing the general model, we present several special cases using $n=2$ sectors to highlight key mechanisms and their relationship to previous work. We then return to the general $n$-sector model.

\subsection{Economic Environment}

Consider an economy with $n$ distinct sectors of production indexed by $j$ (or $i$ ). A representative household derives utility from these $n$ goods according to

$$
\mathbb{E}_{0} \sum_{t=0}^{\infty} \beta^{t} \prod_{j=1}^{n}\left(\frac{c_{j, t}}{\theta_{j}}\right)^{\theta_{j}}, \sum_{j=1}^{n} \theta_{j}=1, \theta_{j} \geq 0
$$

where $\theta_{j}$ is the household's expenditure share on final good $j$.

Each sector produces a quantity, $y_{j, t}$, of good $j$ at date $t$, using a value added aggregate, $v_{j, t}$, and a materials aggregate, $m_{j, t}$, using the technology,

$$
y_{j, t}=\left(\frac{v_{j, t}}{\gamma_{j}}\right)^{\gamma_{j}}\left(\frac{m_{j, t}}{1-\gamma_{j}}\right)^{\left(1-\gamma_{j}\right)}, \gamma_{j} \in[0,1] .
$$

The quantity of materials aggregate, $m_{j, t}$, used in sector $j$ is produced with the technology,

$$
m_{j, t}=\prod_{i=1}^{n}\left(\frac{m_{i j, t}}{\phi_{i j}}\right)^{\phi_{i j}}, \sum_{i=1}^{n} \phi_{i j}=1, \phi_{i j} \geq 0,
$$

where $m_{i j, t}$ denotes materials purchased from sector $i$ by sector $j$. The notion that every sector potentially uses materials from every other sector introduces a first source of interconnectedness in the economy. An input-output (IO) matrix is an $n \times n$ matrix $\Phi$ with typical element $\phi_{i j}$. The columns of $\Phi$ add up to the degree of returns to scale in materials for each sector, in this case unity. The row sums of $\Phi$ summarize the importance of each sector as a supplier of materials to all other sectors. Thus, the rows and columns of $\Phi$ reflect "sell to" and "buy from" shares respectively for each sector.

The value added aggregate, $v_{j, t}$, from sector $j$ is produced using capital, $k_{j, t}$, and labor, $\ell_{j, t}$, according to

$$
v_{j, t}=z_{j, t}\left(\frac{k_{j, t}}{\alpha_{j}}\right)^{\alpha_{j}}\left(\frac{\ell_{j, t}}{1-\alpha_{j}}\right)^{1-\alpha_{j}}, \alpha_{j} \in[0,1] .
$$


Capital accumulation in each sector follows

$$
k_{j, t+1}=x_{j, t}+\left(1-\delta_{j}\right) k_{j, t},
$$

where $x_{j, t}$ represents investment in new capital in sector $j$, and $\delta_{j} \in(0,1)$ is the depreciation rate specific to that sector. Investment in each sector $j$ is produced using the quantity, $x_{i j, t}$, of sector $i$ goods by way of the technology,

$$
x_{j, t}=\prod_{i=1}^{n}\left(\frac{x_{i j, t}}{\omega_{i j}}\right)^{\omega_{i j}}, \sum_{i=1}^{n} \omega_{i j}=1, \omega_{i j} \geq 0 .
$$

Thus, there exists a second source of interconnectedness in this economy in that new capital goods in every sector are potentially produced using the output of other sectors. This additional source of dynamic linkages in the economy, mostly absent from structural multisector studies, is shown to be a key propagation mechanism over the business cycle in vom Lehn and Winberry (2022). Similarly to the IO matrix, a capital flow matrix is an $n \times n$ matrix $\Omega$ with typical element $\omega_{i j}$. The columns of $\Omega$ add up to the degree of returns to scale in investment for each sector which here is unity. The row sums of $\Omega$ indicate the importance of each sector as a supplier of new capital to all other sectors.

The resource constraint in each sector $j$ is given by

$$
c_{j, t}+\sum_{i=1}^{n} m_{j i, t}+\sum_{i=1}^{n} x_{j i, t}=y_{j, t} .
$$

Sectoral change is defined by changes in the composite variable, $A_{j, t}$, that reflect the joint behavior of both TFP and labor growth. In particular, under the maintained assumptions, sectoral value added may be alternatively expressed as

$$
v_{j, t}=A_{j, t}\left(\frac{k_{j, t}}{\alpha_{j}}\right)^{\alpha_{j}}
$$

where

$$
\Delta \ln A_{j, t}=\Delta \ln z_{j, t}+\left(1-\alpha_{j}\right) \Delta \ln \ell_{j, t} .
$$

In this paper, we condition on the observed joint behavior of TFP and labor growth rates, $\left\{\Delta \ln z_{j, t}, \Delta \ln \ell_{j, t}\right\}$, in each sector $j$ and derive their implications for aggregate value added or GDP growth. In particular, we provide general growth accounting expressions that quantify the effects of changes in trend input growth in a given sector in light of its production linkages to all other sectors.

While we condition on observed labor growth rates, the growth accounting expressions we derive are largely unchanged in a model where the allocation of labor is endogenous. In particular, a conventional treatment of labor supply produces a growth expression that is isomorphic to that presented below. In that expression, the way in which capital accumulation and the network features of production determine the influence of different sectors on aggregate growth is unchanged, as are the effects of long-run changes in TFP growth on GDP growth. The key difference is that with endogenous labor supply, the common and 
idiosyncratic components of labor input now carry a structural interpretation. Specifically, the common component is associated with broad demographics such as population growth and how these demographics affect labor input in each sector. The idiosyncratic component reflects sector-specific factors such as those determining the disutility cost of working in different sectors, including a sector-specific Frisch elasticity, or sector-specific labor quality adjustments. ${ }^{15}$

For ease of presentation, we use the following notation throughout the paper: we denote the matrix summarizing value added shares in gross output in different sectors by $\Gamma_{d}=\operatorname{diag}\left\{\gamma_{j}\right\}$, the IO matrix by $\Phi=\left\{\phi_{i j}\right\}$, the capital flow matrix by $\Omega=\left\{\omega_{i j}\right\}$, and the matrix summarizing capital shares in value added in different sectors by $\alpha_{d}=\operatorname{diag}\left\{\alpha_{j}\right\}$.

\subsection{Balanced Growth and Sectoral Multipliers}

We consider a balanced growth path (BGP) where the growth rates of TFP and labor in sector $j$ are given by $g_{j}^{z}$ and $g_{j}^{\ell}$ respectively. From equation (8), it follows that along that path,

$$
\Delta \ln A_{j, t}=g_{j}^{a}=g_{j}^{z}+\left(1-\alpha_{j}\right) g_{j}^{\ell}
$$

We now show that because of production linkages, sources of change in an individual sector, $g_{j}^{a}$, help determine value added growth in every other sector along the balanced growth path. These linkages, therefore, amplify the effects of sector-specific change on GDP growth, and this amplification can be summarized by a multiplier for each sector. As we will see, these multipliers scale the influence of some sectors on GDP growth by up to multiple times their share in the economy.

The sectoral multipliers are readily computed from the production linkages specified in the model. Along the BGP, gross output in sector $j, y_{j, t}$, and its uses, $c_{j, t}, m_{j i, t}$ and $x_{j i, t}$ grow at the same sector-specific rate. Thus, let $g_{j}^{y}$ denote this common growth rate for $y_{j}, c_{j}, m_{j i}$, and $x_{j i}$. Let $g_{j}^{v}, g_{j}^{m}, g_{j}^{k}$ and $g_{j}^{x}$ denote the BGP growth rates of sector $j$ 's inputs $v_{j}, m_{j}, k_{j}$ and $x_{j}$. Let $g^{y}=\left(g_{1}^{y}, \ldots g_{n}^{y}\right)^{\prime}$ and define the $n \times 1$ vectors $g^{v}, g^{m}$, etc., analogously. From (4), note that $g_{j}^{m}=\sum_{i} \phi_{i j} g_{i}^{y}$ (because $m_{i j}$ grows at rate $g_{i}^{y}$ ), so that $g^{m}=\Phi^{\prime} g^{y}$. Similarly, from (6) and (7) $g_{j}^{k}=g_{j}^{x}=\sum_{i} \omega_{i j} g_{i}^{y}$ (because $x_{i j}$ grows at rate $g_{i}^{y}$ ), so that $g^{k}=\Omega^{\prime} g^{y}$. Equation (3) implies $g^{y}=\Gamma_{d} g^{v}+\left(I-\Gamma_{d}\right) g^{m}$, with $g^{v}=g^{a}+\alpha_{d} g^{k}$ from (5). Collecting terms in $g^{y}$ then yields $g^{y}=\Gamma_{d} g^{a}+\Gamma_{d} \alpha_{d} \Omega^{\prime} g^{y}+\left(I-\Gamma_{d}\right) \Phi^{\prime} g^{y}$, so that

$$
g^{y}=\Xi^{\prime} g^{a},
$$

\footnotetext{
${ }^{15}$ See Section 4 of the Technical Appendix. The interpretation or identification of sources of labor growth will necessarily depend on the particular model of endogenous labor supply under consideration. Because our focus is on growth accounting (rather than counterfactuals), we take the observations on labor growth as given whatever their underlying forces. Ngai and Pissarides (2007) explore an alternative framework where the reallocation of labor among consumption goods sectors is an outcome of unbalanced growth among those goods while, at the same time, preserving balanced growth at the aggregate level. Absent from their work, however, are the network considerations and the role of capital in determining network multipliers that are central to this paper. An interesting avenue for future work, therefore, is the study of growth and structural change with production networks.
} 
where $\Xi^{\prime}=\left[I-\Gamma_{d} \alpha_{d} \Omega^{\prime}-\left(I-\Gamma_{d}\right) \Phi^{\prime}\right]^{-1} \Gamma_{d}$ is the generalized Leontief inverse.

Finally, with $g^{v}=g^{a}+\alpha_{d} g^{k}$ and $g^{k}=\Omega^{\prime} g^{y}$, then

$$
g^{v}=\left[I+\alpha_{d} \Omega^{\prime} \Xi^{\prime}\right] g^{a} .
$$

Observe that preference parameters are absent from equation (10) in that balanced growth relationships are ultimately statements about technologies and resource constraints.

Equation (10) describes how the sources of growth in a given sector, $g_{j}^{a}$, affects value added growth in all other sectors, $g_{i}^{v}$. This relationship involves the direct effects of sectors' TFP and labor growth on their own value added growth, $I g^{a}$, and the indirect effects that sectors have on other sectors through the economy's sectoral network of investment and materials, $\alpha_{d} \Omega^{\prime} \Xi^{\prime} g^{a}$. The general Leontief inverse, $\Xi$, is central and summarizes the knock-on effects of sectoral changes through linkages in investment, captured in $\Omega$, and materials, captured in $\Phi$.

Given the vector of sectoral value added growth rates, $g^{v}$, the Divisia aggregate index of GDP growth is $g^{V}=s^{v \prime} g^{v}$ where $s^{v}=\left(s_{1}^{v}, \ldots, s_{n}^{v}\right)$ is a vector of sectoral value added shares in GDP that are constant on the BGP. Thus,

$$
g^{V}=s^{v \prime}\left[I+\alpha_{d} \Omega^{\prime} \Xi^{\prime}\right] g^{a},
$$

so that, holding shares constant,

$$
\frac{\partial g^{V}}{\partial g^{a}}=s^{v}+\Xi \Omega \alpha_{d} s^{v}
$$

The first term in (12) shows the direct effect of $g^{a}$ on the growth rate of GDP and the second term captures the network effects of $g^{a}$ on GDP growth induced by production linkages. ${ }^{16}$ Equation (12), therefore, defines the vector of sectoral multipliers for each of the $j$ sectors.

When no sector uses capital in production, $\alpha_{d}=0$, the drivers of growth sector in $j, g_{j}^{a}$, affect GDP growth only through that sector's share in the economy, $\frac{\partial g^{V}}{\partial g_{j}^{a}}=s_{j}^{v}$. More generally, equations (10) and (12) suggest the presence of a network multiplier effect that varies by sector and that depends not only on the importance of sectoral interactions through the elements of $\Xi$, but also on the extent to which sectors use capital produced by other sectors in their own production, that is the elements in $\Omega$ and $\alpha$. From (9), a change in input growth in sector $j$ influences every other sector $k$ through the network of production linkages summarized by all non-zero $j k$ elements (i.e., from $j$ to $k$ ) of $\Xi$. Induced changes in all sectors $k$ in turn potentially affect investment in every other sector, $i$, through capital flows summarized by $\omega_{k i}$ in $\Omega$, (i.e, from $k$ to $i$ including back to $j$ ). The net effect on GDP growth is the sum of all these interactions. Conveniently, the effects of sectoral changes, $\partial g^{a}$, on GDP growth may be thought of as a direct effect, $s^{v}$,

\footnotetext{
${ }^{16}$ In general, sectoral value added shares in GDP, $s^{v}$, will also depend on the model's underlying parameters including the vector of sources of sectoral growth, $g^{a}$. However, changes in sectoral shares induced by an exogenous change in a sector $k$, $\frac{\partial s_{j}^{v}}{\partial g_{k}^{a}}$, will be mostly inconsequential for overall growth, consistent with Figure 1 and the notion that since shares must sum to $1, \sum_{j} \frac{\partial s_{j}^{v}}{\partial g_{k}^{a}}=0$.
} 
and an additional indirect effect resulting from sectoral linkages, $\Xi \Omega \alpha_{d} s^{v}$. Hence, we define the combined direct and indirect effects of structural change on GDP growth in terms of the vector of sectoral multipliers, $s^{v}+\Xi \Omega \alpha_{d} s^{v}$.

To gain intuition, the next section discusses expressions (10) and (11) above in the context of special cases exemplified in previous work. In particular, we provide examples of sectoral multipliers in Greenwood et al. (1997) (henceforth GHK (1997)) and variations thereof. The Technical Appendix discusses each example in detail as well as the case studied by Ngai and Pissarides (2007). These examples highlight the role of capital accumulation in generating sectoral multipliers. They also underscore the fact that given a network of intermediate goods, all sectors, even those that produce no capital goods, can have sectoral multipliers well in excess of their share in GDP. This last feature of sectoral influence is absent in GHK (1997) which abstracts from intermediate inputs.

\subsection{Relationship to Greenwood, Hercowitz, Krusell (1997)}

The one-sector environment featuring an aggregate production function in GHK (1997) also has an interpretation as a two-sector economy. ${ }^{17}$ Under that interpretation, one sector produces consumption goods (sector 1) and the other investment goods (sector 2), and each sector's production function has the same capital elasticity, $\alpha$. For simplicity, we focus on the discussion in Section III of GHK (1997) which abstracts from the distinction between equipment and structures. Thus, consider a two-sector economy with production given by

$$
\begin{gathered}
c_{t}=y_{1, t}=z_{1, t} k_{1, t}^{\alpha} \ell_{1, t}^{1-\alpha}, \\
x_{t}=y_{2, t}=z_{2, t} k_{2, t}^{\alpha} \ell_{2, t}^{1-\alpha}, \\
k_{t+1}=x_{t}+(1-\delta) k_{t},
\end{gathered}
$$

where factors are freely mobile, $k_{t}=k_{1, t}+k_{2, t}$ and $\ell_{t}=\ell_{1, t}+\ell_{2, t}$, and the constant scale factors in production (which simplify the algebra in the full model) have been dropped. Under the maintained assumptions, this two-sector environment reduces to the one-sector framework with aggregate production described in GHK (1997). That is, there exists a one-sector interpretation of the two-sector economy with associated resource constraint,

$$
c_{t}+q_{t} x_{t}=z_{1, t} k_{t}^{\alpha} \ell_{t}^{1-\alpha},
$$

where $q_{t}=\frac{z_{1, t}}{z_{2, t}}$ is the relative price of investment goods, and aggregate output (in units of consumption goods), $y_{t}=c_{t}+q_{t} x_{t}$, is a function of total factor endowment only, $z_{1, t} k_{t}^{\alpha} \ell_{t}^{1-\alpha}$. To the extent that technical progress in the investment sector, $z_{2, t}$, is generally more pronounced than in the consumption sector, $z_{1, t}$, the relative price of investment goods will decline over time as emphasized by GHK (1997).

Along the balanced growth path, all variables grow at constant but potentially different rates. Because GHK (1997) do not consider materials, there is no distinction between gross output and value added. From

\footnotetext{
${ }^{17}$ See Greenwood et al. (1997), Section V. A.
} 
the market clearing conditions and the form of production technologies, it follows that sectoral output growth rates, $g_{j}^{y}=g_{j}^{v}$, are given by (in terms of the notation introduced above):

$$
g_{j}^{v}=g_{j}^{z}+(1-\alpha) g^{\ell}+\alpha g^{k}=g_{j}^{a}+\alpha g^{k}, j=1,2 .
$$

Equation (14) makes clear that any amplification of sectoral sources of growth, $g_{j}^{a}$, can only take place through capital accumulation. In this case, it follows from the capital accumulation equation that along the BGP, capital grows at the same rate as investment which, in sector 2 (the capital goods producing sector), is also that of output. Thus, we have that

$$
g_{2}^{v}=g^{k}=\frac{1}{1-\alpha} g_{2}^{a} \text { and } g_{1}^{v}=g_{1}^{a}+\frac{\alpha}{1-\alpha} g_{2}^{a} .
$$

Note that the assumption of factor mobility across sectors has only minor implications for the characterization of the BGP. First, even with sector-specific investment, the resource constraint for investment implies that investment and capital grow at the same rate in each sector. Second, with sector-specific labor, the expression for output growth remains as in equation (14) with the only difference being that sector-specific labor growth rates, $g_{j}^{\ell}$, now replace the aggregate labor growth rate, $g^{\ell}$, so that $g_{j}^{a}=g_{j}^{z}+(1-\alpha) g_{j}^{\ell}$.

Aggregate GDP growth is defined as the Divisia index of sectoral value-added growth rates weighted by their respected value added shares. Thus, from equation (15), aggregate GDP growth is

$$
g^{V}=s_{1}^{v}\left(g_{1}^{a}+\frac{\alpha}{1-\alpha} g_{2}^{a}\right)+s_{2}^{v} \frac{1}{1-\alpha} g_{2}^{a}
$$

or alternatively,

$$
g^{V}=s_{1}^{v} g_{1}^{a}+s_{2}^{v} g_{2}^{a}+\frac{\alpha}{1-\alpha} g_{2}^{a} .
$$

In this economy, sector 2 is the sole producer of capital for both sectors 1 and 2 and has both a direct and indirect effect on the aggregate economy. The indirect effect stems from the fact that capital accumulation amplifies the role of sectoral sources of growth. In equation (16), sector 2 contributes $\frac{\alpha}{1-\alpha} g_{2}^{a}>0$ to value added growth in sector 1 and scales its contributions from TFP and labor to its own value added growth by $\frac{1}{1-\alpha}>1$. Thus, in equation (17), the direct aggregate effect of an expansion in sector 2 by way of TFP or labor growth is its share, $s_{2}^{v}$, while its indirect aggregate effect is $\frac{\alpha}{1-\alpha}>0$. It follows that sector 2's sectoral multiplier, $\partial g^{V} / \partial g_{2}^{a}$, is $s_{2}^{v}+\frac{\alpha}{1-\alpha}$. In contrast, because sector 1 produces goods that are only fit for consumption, it only has a direct effect on the aggregate economy. Its sectoral multiplier, $\partial g^{V} / \partial g_{1}^{a}$, is then simply its share in GDP, $s_{1}^{v}$.

A straightforward application of the general framework laid out in the previous section produces the same balanced growth path and sectoral multipliers for sectors 1 and 2 that we have just discussed. In particular, the GHK (1997) economy is a special case with $n=2$ and, since sector 2 is the only sector producing investment goods, $\omega_{1 j}=0$ and $\omega_{2 j}=1$ for $j=1,2$. In addition, each good is produced without intermediate inputs, $\gamma_{j}=1, j=1,2$, and the sectors use the same production functions, $\alpha_{j}=\alpha, j=1,2$. 
These yield the matrices

$$
\Omega=\left(\begin{array}{cc}
0 & 0 \\
1 & 1
\end{array}\right), \Gamma_{d}=I, \alpha_{d}=\alpha I, \text { and } \Xi=\left(I-\Omega \alpha_{d}\right)^{-1}=\left(\begin{array}{cc}
1 & 0 \\
\frac{\alpha}{1-\alpha} & \frac{1}{1-\alpha}
\end{array}\right)
$$

The associated sectoral multipliers are given by the elements of $\left(I+\Xi \Omega \alpha_{d}\right) s^{v}$,

$$
\frac{\partial g^{V}}{\partial g_{1}^{a}}=s_{1}^{v}, \text { and } \frac{\partial g^{V}}{\partial g_{2}^{a}}=s_{2}^{v}+\frac{\alpha}{1-\alpha} .
$$

Actual production linkages are generally more involved than those just discussed. Importantly, even in the context of two sectors and no materials, the simple fact that factor income shares differ across sectors prohibits a one-sector interpretation of the economic environment with an aggregate production function. In this case, the amplification of sources of sectoral growth on GDP growth now depends on a value-added-share weighted average of capital elasticities. ${ }^{18}$

\subsection{Strictly Positive Multipliers for Sectors That Produce No Capital}

Moving beyond GHK (1997), sectoral linkages also reflect a network of materials production. Thus, we now introduce intermediate goods into the GHK (1997) environment. Crucially, when the consumption sector (sector 1) also produces materials for the investment goods sector (sector 2), the growth rate of capital depends on both sectors 1 and 2. Therefore, both sectors 1 and 2 now have indirect effects on long-run GDP growth over and above their share in the economy.

We illustrate these points via a simple network of intermediate goods. Here, sector 1 produces not only consumption goods but also materials, $m_{1, t}$, used by sector 2 . Similarly, sector 2 still produces capital goods for both sectors but also materials, $m_{2, t}$, used by sector 1 . Since sector 1 now produces consumption goods and intermediate goods, we refer to sector 1 as the Nondurables sector. Thus, in terms of our general notation, we have that $\gamma_{j} \neq 1, \omega_{1 j}=0$ and $\omega_{2 j}=1$ for $j=1,2$. Moreover, the relevant resource constraints in sectors 1 and 2 are now

$$
c_{t}+m_{1, t}=y_{1, t}=\left[z_{1, t} k_{1, t}^{\alpha_{1}} \ell_{1, t}^{1-\alpha_{1}}\right]^{\gamma_{1}} m_{2, t}^{1-\gamma_{1}}
$$

and

$$
x_{t}+m_{2, t}=y_{2, t}=\left[z_{2, t} k_{2, t}^{\alpha_{2}} \ell_{2, t}^{1-\alpha_{2}}\right]^{\gamma_{2}} m_{1, t}^{1-\gamma_{2}},
$$

while the rest of the production side of the economy is as in the previous examples.

In this case, a calculation shows that the BGP growth rate of capital is given by

$$
g^{k}=\frac{\left(1-\gamma_{2}\right) \gamma_{1} g_{1}^{a}+\gamma_{2} g_{2}^{a}}{\Delta}
$$

\footnotetext{
${ }^{18}$ See Section 3 of the Technical Appendixfor exact expressions.
} 
where $\Delta=1-\gamma_{2} \alpha_{2}-\left(1-\gamma_{2}\right)\left[\gamma_{1} \alpha_{1}+\left(1-\gamma_{1}\right)\right]$. The growth rate of GDP is then

$$
g^{V}=s_{1}^{v} g_{1}^{a}+s_{2}^{v} g_{2}^{a}+\left(s_{1}^{v} \alpha_{1}+s_{2}^{v} \alpha_{2}\right) g^{k}
$$

Two important observations emerge relative to the previous examples. First, because the Nondurable Goods sector now produces intermediate inputs for the investment sector, the growth rate of capital goods in equation (18) reflects sources of growth in both sectors, $g_{1}^{a}$ and $g_{2}^{a}$. Hence, unlike in the previous section, both sectors 1 and 2 in equation (19) have an additional indirect effect on long-run GDP growth, $\left(s_{1}^{v} \alpha_{1}+s_{2}^{v} \alpha_{2}\right) \frac{\partial g^{k}}{\partial g_{1}^{a}}$ and $\left(s_{1}^{v} \alpha_{1}+s_{2}^{v} \alpha_{2}\right) \frac{\partial g^{k}}{\partial g_{2}^{a}}$ respectively, over and above their shares in the economy, $s_{1}^{v}$ and $s_{2}^{v}$. Second, from equation (19), the indirect effect from sector 2 on GDP growth dominates that from sector 1 if and only if its contributions to overall capital growth, $\frac{\partial g^{k}}{\partial g_{2}^{a}}$, are larger than the corresponding contributions from sector 1, $\frac{\partial g^{k}}{\partial g_{1}^{a}}$. From equation (18), this condition holds if and only if

$$
\gamma_{2}>\left(1-\gamma_{2}\right) \gamma_{1}
$$

This will not be true, for example, in economies where the value added share in gross output of the capital sector, $\gamma_{2}$, is relatively small. In that case, the main input into the production of capital goods are intermediate inputs from the non-durables sector. That sector, therefore, ends up having more influence on aggregate growth.

Substituting (18) into (19) yields the sectoral multipliers: ${ }^{19}$

$$
\frac{\partial g^{V}}{\partial g_{1}^{a}}=s_{1}^{v}+\frac{\left(s_{1}^{v} \alpha_{1} \gamma_{1}\left(1-\gamma_{2}\right)+s_{2}^{v} \alpha_{2} \gamma_{1}\left(1-\gamma_{2}\right)\right)}{\Delta} \text { and } \frac{\partial g^{V}}{\partial g_{2}^{a}}=s_{2}^{v}+\frac{s_{1}^{v} \alpha_{1} \gamma_{2}+s_{2}^{v} \alpha_{2} \gamma_{2}}{\Delta} .
$$

Generally, the main lesson from these examples is that network production linkages and capital accumulation are the key components that lead to sectoral multipliers along the balanced growth path. Furthermore, the implied amplification of idiosyncratic sources of growth on GDP growth can arise in any sector, including those producing only Nondurable Goods.

Finally, we note a caveat to our results: they all pertain to a closed economy. Cavallo and Landry (2010) argue that imports are also a source of equipment capital accumulation, and more generally Basu et al. (2013) argue for including trade when studying investment-specific technical change with production networks. In Section 3.5 of the Technical Appendix, we introduce traded investment goods into the GHK (1997) framework along the lines of Basu et al. (2013). In that case, the amplification effects of production networks and capital accumulation also reflect variations in the terms of trade, scaled by the share of foreign investment goods in total investment. In this example, the quantitative implications of traded capital goods

${ }^{19}$ Equivalently, these multipliers can be computed from the general formula (12) using the matrices for this model:

$$
\Omega=\left(\begin{array}{ll}
0 & 0 \\
1 & 1
\end{array}\right), \alpha_{d}=\left(\begin{array}{cc}
\alpha_{1} & 0 \\
0 & \alpha_{2}
\end{array}\right), \Gamma_{d}=\left(\begin{array}{cc}
\gamma_{1} & 0 \\
0 & \gamma_{2}
\end{array}\right) \text {, and } \Phi=\left(\begin{array}{ll}
0 & 1 \\
1 & 0
\end{array}\right) \text {. }
$$


Figure 8: Investment Network

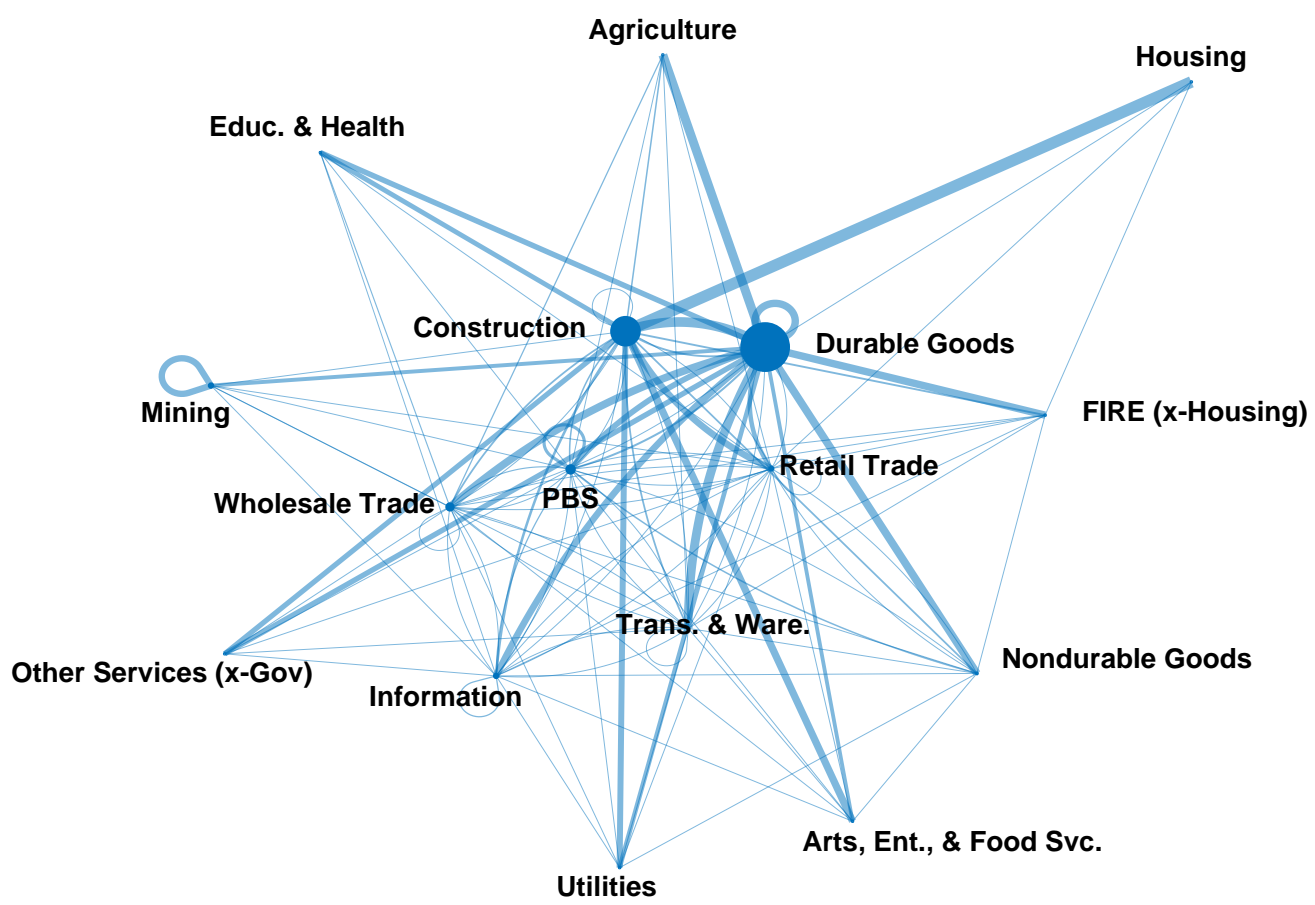

Notes: This figure shows the investment network as a graph, where capital flows are represented by edges between nodes representing sectors. A sector with a larger node indicates that other sectors spend a larger share of their capital expenditures on average from that sector. A wider edge between two nodes reflects larger bi-directional capital flows relative to all other capital flows. See the capital flow table in Section 8 of the Technical Appendix.

remain limited though they have increased over time.

\section{$5 \quad$ Quantitative Findings}

This section puts together the empirical findings from Section 3 and model insights from Section 4 . It shows that sector-specific trends have played a dominant role in driving the trend rate of growth in GDP over the postwar period. We estimate that this aggregate trend rate of growth has fallen by almost 3 percentage points between 1950 and today. 


\subsection{Model Parameters}

We first outline the construction of model parameters, a procedure that follows mostly Foerster et al. (2011) and is governed by the BEA input-output and capital flow accounts. ${ }^{20}$

In our benchmark economy, value-added shares in gross output $\left\{\gamma_{j}\right\}$, capital shares in value added, $\left\{\alpha_{j}\right\}$, and material bundle shares, $\left\{\phi_{i j}\right\}$, are obtained from the 2015 BEA make and use tables. The make table tracks the value of production of commodities by sector, while the use table measures the value of commodities used by each sector. We combine the make and use tables to yield, for each sector, a table whose rows show the value of a sector's production going to other sectors (materials) and households (consumption), and whose columns show payments to other sectors (materials) as well as labor and capital. Thus, a column sum represents total payments from a given sector to all other sectors, while a row sum gives the importance of a sector as a supplier to other sectors. We then calculate material bundle shares, $\left\{\phi_{i j}\right\}$, which constitute the IO matrix, as the fraction of all material payments from sector $j$ that goes to sector $i$. Similarly, value-added shares in gross output, $\left\{\gamma_{j}\right\}$, are calculated as payments to capital and labor as a fraction of total expenditures by sector $j$, while capital shares in value added, $\left\{\alpha_{j}\right\}$, are payments to capital as a fraction of total payments to labor and capital.

The parameters that determine the production of investment goods, $\left\{\omega_{i j}\right\}$, are chosen similarly in accordance with the BEA capital flow table from 1997, the most recent year in which this flow table is available. The capital flow table shows the flow of new investment in equipment, software, and structures towards sectors that purchase or lease it. By matching commodity codes to sectors, we obtain a table that has entries showing the value of investment purchased by each sector from every other sector. A column sum represents total payments from a given sector for investment goods to all other sectors, while a row sum shows the importance of a sector as a supplier of investment goods to other sectors. Hence, the investment bundle shares, $\left\{\omega_{i j}\right\}$, which constitute the capital flow matrix are estimated as the fraction of payments for investment goods from sector $j$ to sector $i$, expressed as a fraction of total investment expenditures made by sector $j$.

Conditional on these parameters, equation (10) gives sectoral value added growth along the balanced growth path. In constructing aggregate GDP growth from these sectoral value added growth rates, we rely on the full sample mean value added shares from the KLEMS data that were used in our empirical analysis. Recall also that in Figure 1, we explored using different definitions of value added shares in calculating GDP growth. While this did not lead to meaningful differences in aggregate growth, to the extent that these shares are changing over time as do input-output relationships, the model might nevertheless yield more material differences in the implied sectoral multipliers. Thus, in the Technical Appendix, we show that our benchmark sectoral multipliers are robust to versions of the model informed by mean value added shares for the first and last 15 years, and the 1960 and 1997 make and use tables.

\footnotetext{
${ }^{20}$ Section 8 of the Technical Appendix contains a more detailed description of the procedure, and for the 16 sectors considered in this paper it displays the capital flow matrix, Table A10, the IO matrix, Table A11, and the associated generalized Leontief inverse, Table A12.
} 


\subsection{Production Linkages in the U.S. Economy}

The production of investment goods in the U.S. turns out to be concentrated in relatively few sectors. Construction and Durable Goods produce close to 80 percent of the capital in almost every sector. Put another way, as shown in Figure 8, we can think of the Construction and Durable Goods sectors as investment hubs in the production network. Construction comprises residential and non-residential structures including infrastructure. The bulk of capital produced by the Durable Goods sector resides in motor vehicles, machinery, and computer and electronic products. Other sectors recorded as producing capital goods for the U.S. economy include Wholesale Trade, Retail Trade, and Professional and Business Services. In the Professional and Business Services sector, the notion of capital produced for other sectors is overwhelmingly composed of computer system designs and related services. The BEA distinguishes between materials and capital goods by estimating the service life of different commodities and, consistent with the annual time period used in this paper, commodities expected to be used in production within the year are defined as materials. As a practical matter, however, the distinction between materials and investment goods is not always straightforward. We address measurement issues separately in Section $6 .^{21}$

Compared to the capital flow matrix, the production of intermediate goods is somewhat less concentrated as all sectors produce materials for all other sectors to varying degrees. However, from the IO matrix, Professional and Business Services and FIRE stand out as suppliers of materials. These two sectors are the largest suppliers of intermediate goods in the U.S. production network, making up roughly 20 percent of materials expenditures across sectors. A key difference, however, is that intermediate inputs produced by FIRE are used extensively in Housing which is consumed mostly as a final good. In contrast, Professional and Business Services is the largest supplier of intermediate goods to Durable Goods (other than those Durable Goods purchases from itself). After FIRE and Professional and Business Services, the next largest suppliers of materials are Durable Goods and Nondurable Goods which make up around 11 percent of materials expenditures across sectors on average, or $1 / 2$ of those spent on Professional and Business Services.

In contrast to the sectors that play a key role in the U.S. production network, output produced in sectors such as Agriculture, Forestry, Fishing, Housing, and Hunting, Entertainment and Food Services is mostly consumed as final goods.

\footnotetext{
${ }^{21}$ Major revisions of the National Income Accounts (NIAs) broadened the concept of capital by including expenditures on software in 1999, and expenditures on R\&D and entertainment, literary, and artistic originals in 2013. These investments now come under the heading of intellectual property products (IPPs). While the KLEMS data include a broad measure of IPP capital, the 1997 capital flow tables include software investment but not all IPP investment categories. The share of missing investment is less than 10 percent in 1960 and about 15 percent today. As also noted in Foerster et al. (2011), capital flow tables do not account for an industry's purchases of used capital goods and likely miss a portion of maintenance and repair using within sector resources. Results presented here are robust to adjustments that assume up to an additional 25 percent of capital expenditures within sectors. Finally, we abstract from land and inventories in the production structure. Including inventories and land is conceptually straightforward but data quality at the sector level remain an issue. Fernald (2014) includes land and inventories into a GHK (1997) growth accounting framework and finds only a marginal effect.
} 
Table 4: Sectoral Multipliers

\begin{tabular}{lccc}
\hline \hline Sector & $s^{v}$ & $\Xi \Omega \alpha_{d} s^{v}$ & $\left(I+\Xi \Omega \alpha_{d}\right) s^{v}$ \\
\hline Agriculture & 0.03 & 0.01 & 0.03 \\
Mining & 0.02 & 0.03 & 0.05 \\
Utilities & 0.02 & 0.01 & 0.03 \\
Construction & 0.05 & 0.12 & 0.17 \\
Durable Goods & 0.13 & 0.28 & 0.42 \\
Nondurable Goods & 0.09 & 0.03 & 0.13 \\
Wholesale Trade & 0.07 & 0.08 & 0.15 \\
Retail Trade & 0.08 & 0.02 & 0.11 \\
Trans. \& Ware. & 0.04 & 0.03 & 0.07 \\
Information & 0.05 & 0.03 & 0.08 \\
FIRE (x-Housing) & 0.10 & 0.03 & 0.14 \\
PBS & 0.09 & 0.16 & 0.25 \\
Educ. \& Health & 0.06 & 0.00 & 0.06 \\
Arts, Ent., \& Food Svc. & 0.04 & 0.01 & 0.04 \\
Other Services (x-Gov) & 0.03 & 0.01 & 0.04 \\
Housing & 0.09 & 0.00 & 0.09 \\
\hline
\end{tabular}

Notes: This table decomposes each sector's total multiplier (column 3) into a direct effect (column 1) and an indirect effect (column 2). The sums do not necessarily add up because of rounding.

\subsection{Sectoral Multipliers}

Table 4 shows the direct and combined effects of sectoral sources of growth on GDP growth. The importance of Durable Goods, Professional and Business Services, and Construction, means not only that their value added share in GDP is large, 13, 9 and 5 percent respectively, but also that they have large spillover effects on other sectors. In particular, Durable Goods and Professional and Business Services have the two largest sectoral multipliers, 0.42 and 0.25 respectively, while Construction's multiplier exceeds three times its value added share in GDP at 0.17 given its central role in the investment network. Considering that trend TFP growth in Construction fell by almost 5 percentage points between 1950 and 1980 in Figure 4, this gives us, all else equal, a roughly 0.85 percentage point decline in trend GDP growth from that sector alone during that period. Similarly, the over 6 percentage point collapse in the trend growth rate of TFP in Durable Goods since 2000 would have on its own contributed roughly a 2.5 percentage point decline in trend GDP growth.

It is also apparent from Table 4 that the effects of sectoral change on GDP growth are always at least as large as sectors' value added shares in GDP. Sectoral network multipliers almost triple the share of Professional and Business Services, from 0.09 to 0.25, and doubles that of Wholesale Trade, from 0.07 to 0.15. In other sectors, such as Agriculture, Forestry, Fishing and Hunting, or Housing, the network multipliers are 
Figure 9: Trend Growth Rate in GDP: Data and Model

(percentage points at annual rate)

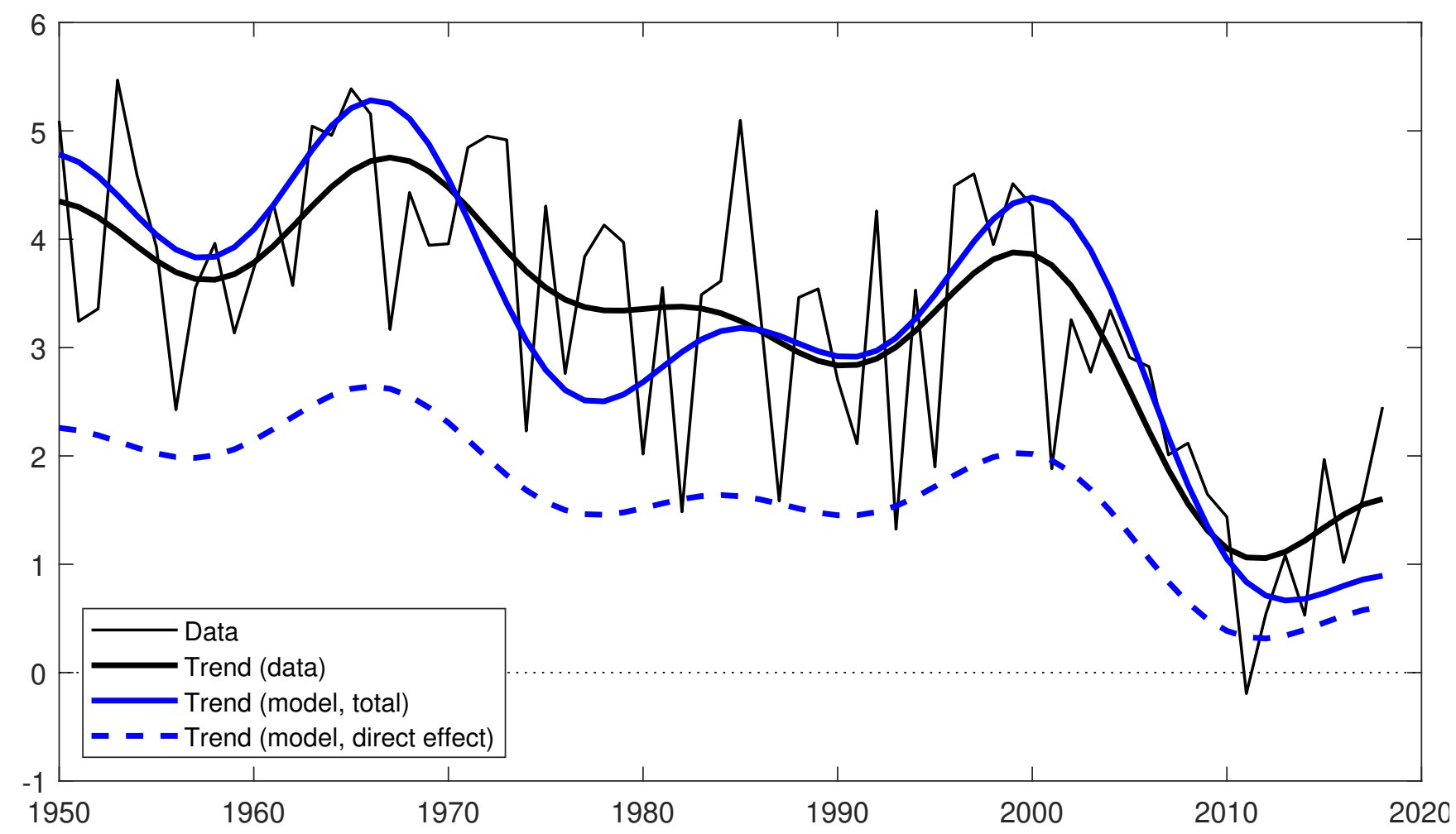

Notes: The figure shows the cyclically adjusted GDP growth rate (thin black line) along with its low-frequency trend (thick black line). Also shown are the model-implied trend using the low-frequency trends of labor and TFP growth (solid blue line), and the trend implied by only the direct effects of labor and TFP based solely on value-added shares (dashed blue line).

smaller since these sectors produce mainly final consumption goods. Because the same network relationships embodied in the capital flow matrix, $\Omega$, and the IO matrix, $\Phi$, determine the importance that sectors have in the economy both as a share of value added and through their spillover effects, sectors with relatively larger shares in GDP will also tend to be associated with large network multipliers.

A key implication of Table 4 is that the effects of sectoral change on GDP growth arise in part through a composition effect. Therefore, secular changes in GDP growth can take place without observable changes in aggregate TFP growth. For example, consider purely idiosyncratic changes in TFP growth, $\partial g_{u, j}^{u, z}$, that leave aggregate TFP growth unchanged, $\sum_{j=1}^{n} s_{j}^{v} \partial g_{u, j}^{z}=0$. In other words, the direct effect of sectoral TFP growth in this case is zero. Despite aggregate TFP growth not changing, these idiosyncratic changes will nevertheless have an (indirect) effect on GDP growth since the sum of sectoral multipliers is larger than 1. 


\subsection{Historical Decomposition of the Trend Growth Rate of GDP}

The various sectoral multiplier calculations we have just carried out depend on the balanced growth equations (10) and (11). These equations hold only in steady state and ignore endogenous transitional dynamics that are potentially important in explaining variations over the business cycle. However, because our empirical focus is on variations in growth rates with periodicities longer than 17 years, we abstract from these transitional dynamics and apply the formulas (10) and (11) directly to the trend growth rates of TFP and labor extracted in Section $3, g_{i, t}^{z}$ and $g_{i, t}^{\ell}$, as an approximation. ${ }^{22}$ In addition, we then explore how our estimates of common, $\left(\lambda_{i}^{z} g_{i, t}^{z}, \lambda_{i}^{\ell} g_{i, t}^{\ell}\right)$, and sector-specific, $\left(g_{u, i, t}^{z}, g_{u, i, t}^{\ell}\right)$, trend input growth have historically contributed to the trend growth rates of sectoral value added and GDP. Thus, we compute the trend growth rates of sectoral value added as,

$$
g_{t}^{v}=\left[I+\alpha_{d} \Omega^{\prime} \Xi^{\prime}\right]\left(\lambda^{z} g_{f, t}^{z}+g_{u, t}^{z}+\left(I-\alpha_{d}\right)\left(\lambda^{\ell} g_{f, t}^{\ell}+g_{u, t}^{\ell}\right)\right)
$$

where $g_{t}^{v}=\left(g_{1, t}^{v}, \ldots, g_{n, t}^{v}\right)$, and $\left(\lambda^{z}, \lambda^{\ell}\right)$ are vectors containing the factor loadings from (1). GDP trend growth is then

$$
g_{t}^{V}=s^{v \prime} g_{t}^{v}
$$

Figure 9 depicts the annual growth rate of GDP and its trend in black (previously shown in Figure 2) together with the corresponding trend growth rate computed from the balanced growth multipliers (in solid blue) and its contribution from the direct effect using sectors' value added shares only (in dashed blue), $s^{v \prime} I\left(g_{t}^{z}+\left(I-\alpha_{d}\right) g_{t}^{\ell}\right)$. In all, trend GDP growth fell by nearly 3 percentage point over the postwar period. Importantly, the sizable gap between the trend with direct effects only and the full model trend implies that the indirect effects stemming from network production linkages constitute a significant component of trend GDP growth. There is a notable discrepancy between model and data in the 1970s, when the balanced growth multipliers suggest a larger decline in trend GDP growth rates than in the data. In that period, periodicities longer that 17 years may not be adequate to capture the required adjustment to capital implied by the model.

Figure 10 decomposes the trend growth rate of GDP implied by the model into its components derived from common factors and sector-specific factors. The model indicates that sector-specific or unique factors in trend labor and TFP growth (panel (b)) have historically accounted for roughly $3 / 4$ of the long-run changes in GDP growth. Conversely, only about 1/4 of the variation in trend GDP growth since 1950 has come from common sources of input growth (panel (a)). This is despite common factors explaining roughly $2 / 3$ of the variation in the trend growth rate of aggregate labor noted in Section 3. To understand this finding, recall that some sectors that have large sectoral multipliers such as Durable Goods or Construction

\footnotetext{
${ }^{22}$ Our results then reflect the long-run amplifying effects of production linkages by way of capital accumulation. Despite abstracting from the transition dynamics, Section 9 of the Technical Appendix shows that the model's implied trend sectoral capital growth rates match their counterparts in the data well, with the exception of Mining which carries a small sectoral multiplier.
} 
Figure 10: Decomposition of the Trend Growth Rate in GDP (percentage points at annual rate)

(a) Common Factor

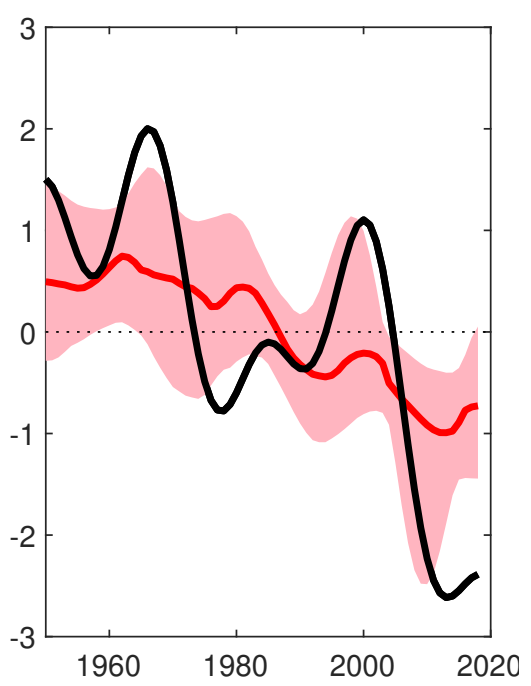

(b) Sector-Specific

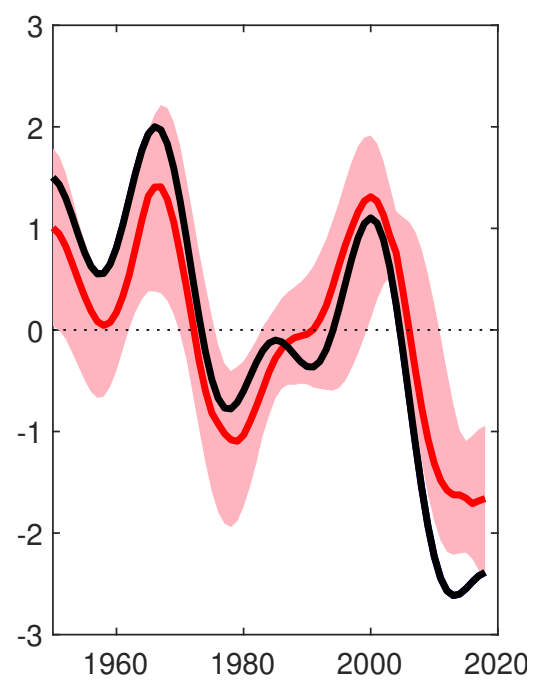

(c) Posterior Distribution for Fraction of Variance Attributed to Common Factor $\left(R_{f}^{2}\right)$

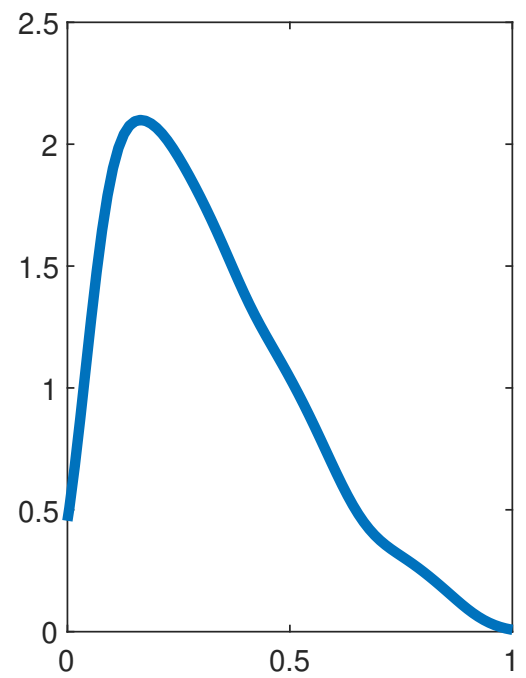

Notes: Panels (a) and (b) show the (demeaned) model-implied trend GDP growth (black line), and its decomposition into changes due to the common factor and sector-specific factors (red lines). The overall trend in black is $s^{v \prime}\left[I+\alpha_{d} \Omega^{\prime} \Xi^{\prime}\right]\left(g_{t}^{z}+\left(I-\alpha_{d}\right) g_{t}^{\ell}\right)$. The posterior median estimates of common and sector specific components, along with their 68 percent credible intervals in red, are respectively $s^{v \prime}\left[I+\alpha_{d} \Omega^{\prime} \Xi^{\prime}\right]\left(\lambda^{z} g_{f, t}^{z}+\left(I-\alpha_{d}\right) \lambda^{\ell} g_{f, t}^{\ell}\right)$ and $s^{v \prime}\left[I+\alpha_{d} \Omega^{\prime} \Xi^{\prime}\right]\left(g_{u, t}^{z}+\left(I-\alpha_{d}\right) g_{u, t}^{\ell}\right)$. Panel (c) shows the posterior distribution for the fraction of the variance in trend GDP growth attributed to the common factor.

(Table 3) also have large variations in trend input growth that are almost entirely driven by idiosyncratic factors (Figures 6 and 7 ).

Panel (c) plots the posterior density for $R_{f}^{2}$, the fraction of the variance in trend GDP growth explained by common sources. The median of the posterior for $R_{f}^{2}$ is 0.26 , the mode is less than 0.20 , and 70 percent of the posterior mass is associated with values of $R_{f}^{2}$ that are less than 0.40 . Thus, these results suggest that most of the long-run evolution of GDP growth has historically stemmed from sector-specific factors.

The results reported thus far use the benchmark priors. Recall from Section 3 that these priors were relatively uninformative except for the factor loadings. In particular, the prior for $\lambda^{\ell}$ was $\lambda^{\ell} \sim N\left(\mathbf{1}, \mathbf{P}_{\ell}\right)$, where $\mathbf{P}_{\ell}=\eta^{2}\left(I_{16}-s_{\ell}\left(s_{\ell}^{\prime} s_{\ell}\right)^{-1} s_{\ell}^{\prime}\right)$ and an analogous prior was used for $\lambda^{z}$. These priors enforced the normalization that $s_{\ell}^{\prime} \lambda^{\ell}=s_{v}^{\prime} \lambda^{z}=1$, so that unit changes in $f_{t}^{\ell}$ and $f_{t}^{z}$ lead to unit changes in the long-run growth rate of aggregate labor and TFP. The parameter $\eta$ then governed how aggressively the estimates of $\lambda_{i}^{\ell}$ or $\lambda_{i}^{z}$ are shrunk toward their mean of unity. The benchmark results use $\eta=1$. Smaller values of $\eta$ shrink the estimates closer to 1 while larger values of $\eta$ allows them to deviate from 1 more than the baseline model. Thus, we now explore the robustness of our findings to alternative priors, $\eta=1 / 2$ and $\eta=2$. In addition, we also run the model using $q=6$ which captures long-run variations with periodicities longer 
Figure 11: Robustness to Changes in Statistical Model

(a) Model: $q=8, \eta=1.0, R_{f}^{2}=0.28(0.12,0.52)$

Common

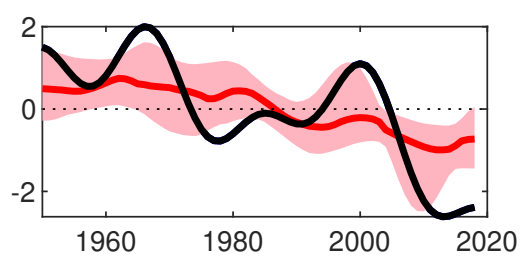

Sector-Specific

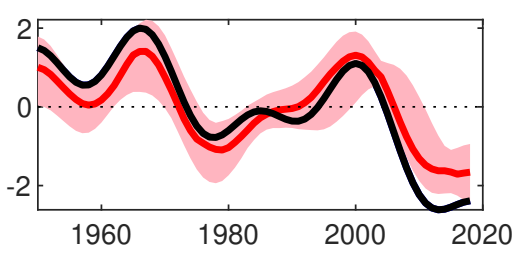

Density, $R_{f}^{2}$ (Common)

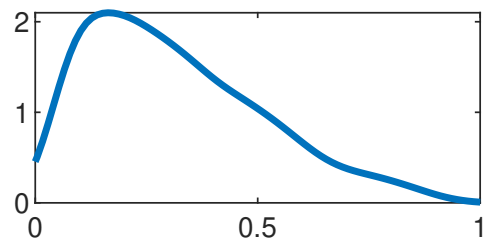

(b) Model: $q=8, \eta=0.5, R_{f}^{2}=0.26(0.12,0.46)$

Common

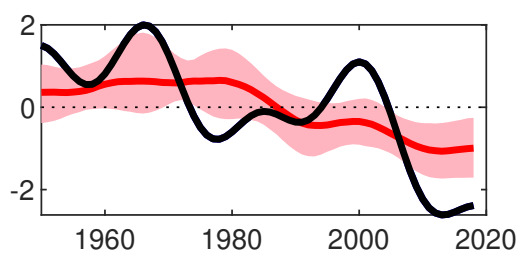

Sector-Specific

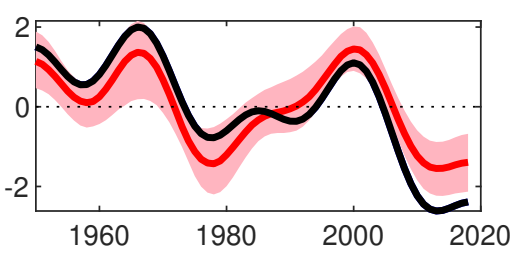

Density, $R_{f}^{2}$ (Common)

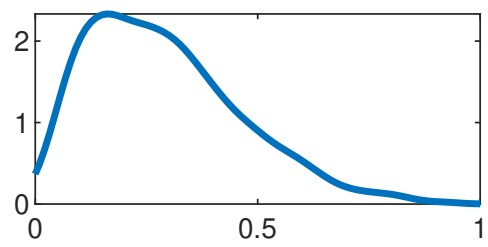

(c) Model: $q=8, \eta=2.0, R_{f}^{2}=0.25(0.11,0.45)$

Common

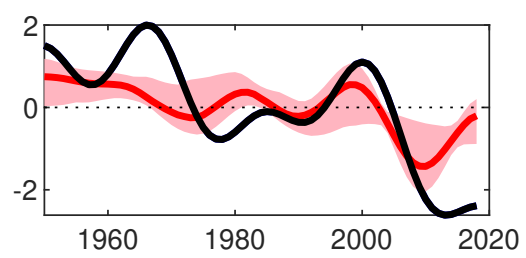

Sector-Specific

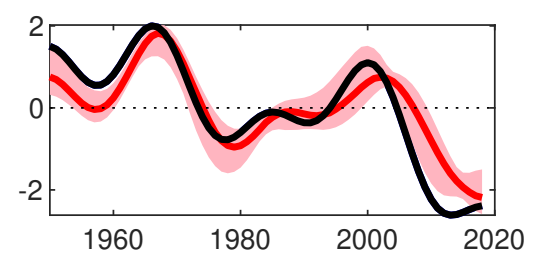

Density, $R_{f}^{2}$ (Common)

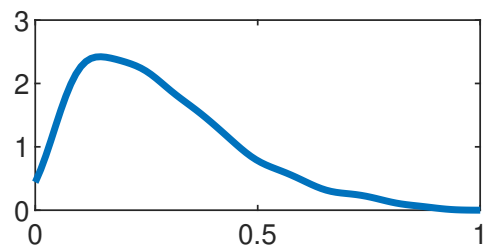

(d) Model: $q=6, \eta=1.0, R_{f}^{2}=0.37(0.19,0.60)$

Common

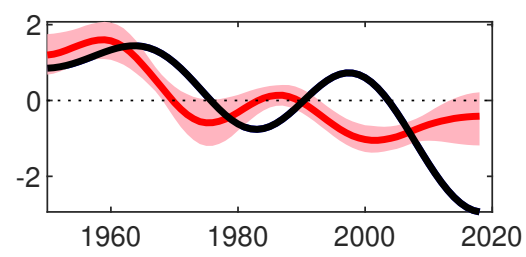

Sector-Specific

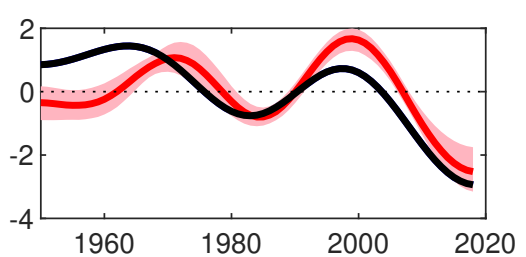

Density, $R_{f}^{2}$ (Common)

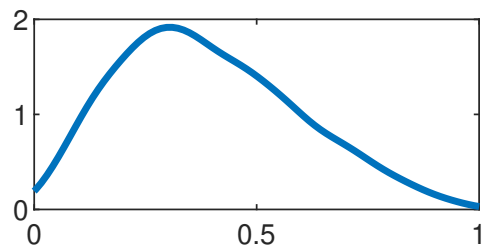

Notes: See notes for Figure 10. Each vertical panel of the Figure shows results for a different specification of the prior distribution, $\eta$, or long-run periodicities, $q$.

than $2 \times 69 / 6=23$ years.

Figure 11 summarizes the findings from these robustness exercises by reproducing Figure 10 for each of these alternative models It is clear from the figure that across all cases, contributions from common sources of trend input growth to the long-run evolution of GDP growth remain limited. Median estimates of $R_{f}^{2}$ 
range from 0.28 to 0.37 with posterior distributions that place the bulk of their mass between 0 and 0.5 . We thus conclude that the result that sector-specific forces are the primary driver of trend GDP growth are robust to changes in the priors for the factor loadings and to increasing the periodicity used that defines long-run trends.

Given that sector-specific (rather than common) trends have played a dominant role in driving trend GDP growth over the postwar period, Figure 12 gives the historical trend contributions to aggregate GDP growth from the sector-specific components for each sector. Two sectors stand out, Construction and Durable Goods. Recall that U.S. trend GDP growth fell by approximately 3 percentage points between 1950 and 2018. Comparing the beginning and the end of the sample, Figure 12 indicates that Durable Goods alone contributed around 1 percentage point of that decline and Construction 0.75 percentage points. However, there are also important differences in the timing and variation of those sectoral contributions. Construction contributed roughly a 1 percentage point decline in trend GDP growth between 1950 and 1980 and was essentially flat thereafter. In contrast, Durable Goods played a key role in raising trend GDP growth in the 1980's and 1990's before contributing an almost 2 percentage point decline in trend GDP growth after 2000. Nondurable goods also notably contributed to the post-war decline in trend GDP growth at roughly 0.5 percentage points over the entire sample period, though offset somewhat by Mining after 1980 .

Strikingly, many other sectors show relatively flat contributions to aggregate trend growth over 1950 to 2018, between -0.1 and 0.1 percentage points. Perhaps even more surprising, no sector has contributed any steady significant increase to the trend growth rate of GDP over that period.

\section{Discussion and Implications for Future Research}

The findings we have just described result from two key notions explored above. One is largely empirical and relates to the size of variations in trend TFP and labor growth in each sector. The other is more theoretical and relates to the size of a sector's multiplier given its place in the production network. The paper then brings together two related, though so far mostly distinct, literatures. One addresses investment-specific technical change, explored by Greenwood et al. (1997) and others, and the other studies the effects of production networks, underscored for example by Acemoglu et al. (2012) and Baqaee and Farhi (2019). We extend Greenwood et al. (1997) by considering the full set of materials and investment linkages that characterize U.S. sectoral production. At the same time, we introduce their emphasis on dynamics and capital accumulation into the static production network environments of Acemoglu et al. (2012). The analysis then provides new results and more general insights into each of these literatures separately. Importantly, these results combined with our empirical trend analysis provide the basis for a more complete and accurate picture of the drivers of the secular decline in GDP growth. 
Figure 12: Sector-Specific Contributions to the Trend Growth Rate of GDP (percentage points at annual rate)

Agriculture

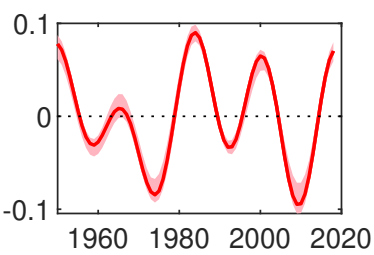

Durable Goods

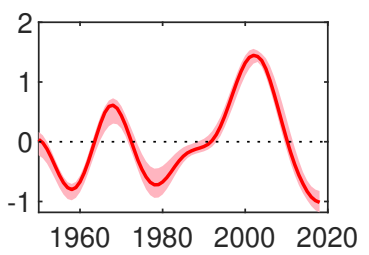

Trans. \& Ware.

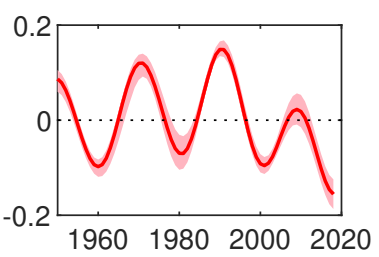

Educ. \& Health

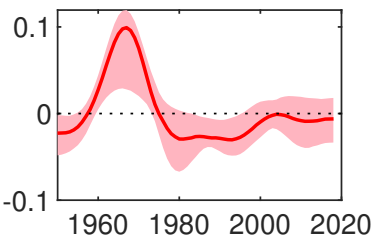

Mining

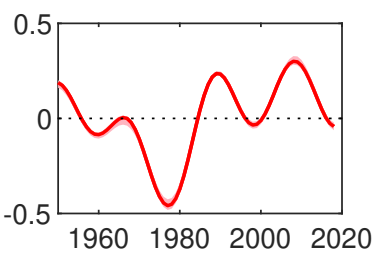

Nondurable Goods

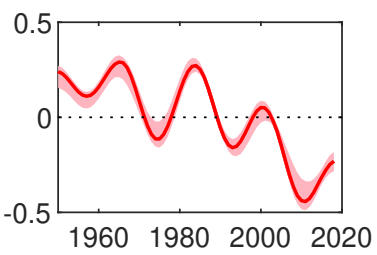

Information

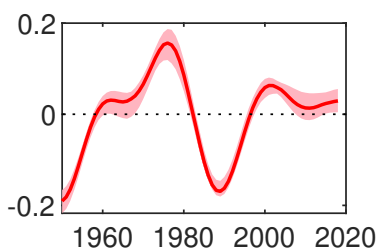

Arts, Ent. \& Food Svc.

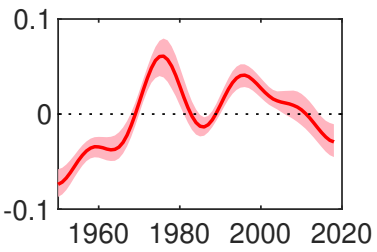

Utilities

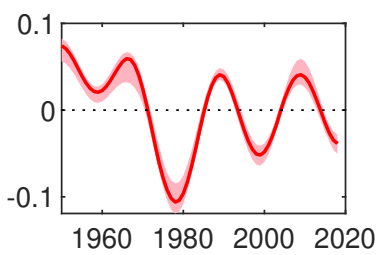

Wholesale Trade

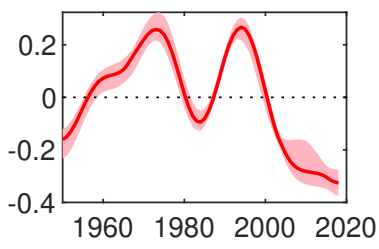

FIRE (x-Housing)

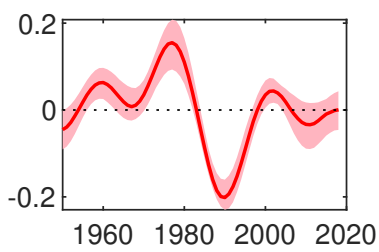

Other Services (x-Gov.)

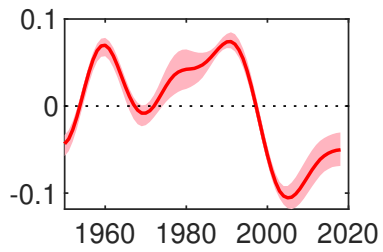

Construction

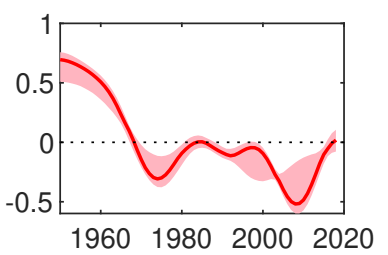

Retail Trade

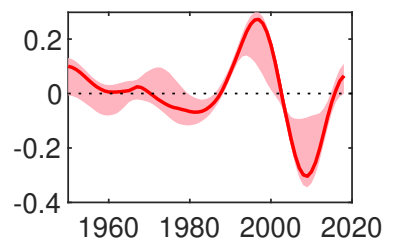

PBS

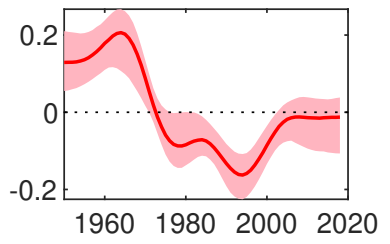

Housing

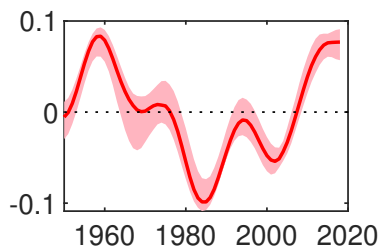

Notes: Each panel shows the implications of sector-specific trends for the trend growth rate of GDP using the modelbased multipliers. The solid lines denote the posterior median and the shaded areas are (pointwise) equal-tail $68 \%$ credible intervals.

\subsection{Production Networks and Investment-Specific Technical Change}

The literature on investment-specific technical change (ISTC) has relied for the most part on a particular set of key simplifying assumptions. One is a direct relationship between the relative price of investment goods and the relative productivity of the capital producing sector. Another is that there is no distinction between producer prices and final demand prices. Finally, abstracting from sectoral linkages in materials means that only the capital producing sector can have a sectoral multiplier that exceeds its value added share. In practice, however, as illustrated in the two-sector example of Section 4, even sectors that produce 
only services will have a multiplier effect when those services are used by capital-producing sectors.

Sectoral linkages break down the one-to-one relationship between relative productivity and relative price. In Greenwood et al. (1997), this would mean that investment-specific productivity, $1 / q_{t}$, is no longer the relative price of investment goods, $q_{t}$, as in equation (13) above. ${ }^{23}$ In Section 2 of the Technical Appendix, we show a more general mapping where productivity growth in any one sector potentially contributes to changes in producer prices in all other sectors. Analogous to equation (10), this more complex mapping reflects the influence of production linkages, $\Omega$ and $\Phi$, through the general Leontief inverse, $\Xi^{\prime}$. The Technical Appendix then further shows that the model's quantitative implications for producer prices generally matches well their data counterparts across sectors. ${ }^{24}$ That said, as in most previous work, we continue to abstract from the distinction between producer prices and final demand prices. To make that distinction, including for investment prices, one needs to model the allocation of the cost components from intermediation industries, which include Retail Trade, Wholesale Trade, and Transportation, to final goods. For now, we leave exploring these relationships to future work. ${ }^{25}$

With only two sectors and no intermediate inputs, the last key limitation of Greenwood et al. (1997) is that the effects of TFP increases in a sector that produces mainly intermediate goods or services cannot be easily traced. In particular, these would show up partly as a decline in the relative price of investment goods when those services are purchased by capital-producing sectors. Therefore, without a more structural description of the sectoral production network, any effects on growth risk being attributed to capital sectors rather than the original service sector. For example, while Professional and Business Services (PBS) play a notably less prominent role in the investment network than does Construction in Figure 8, Table 4 shows that PBS nevertheless has a larger overall sectoral multiplier than Construction, 0.25 versus 0.17. Moreover, while the ratio of Construction's sectoral multiplier to its value added share exceeds that of PBS, both are around three. The reason is that while PBS' role in the investment network is small, it is a key supplier of materials including to Durable Goods. Figure 12 shows that the contributions from PBS to trend variations in GDP growth are smaller than those from Construction. However, this finding arises not because PBS is less influential in the overall production network but because variations in trend TFP growth in PBS have been historically less important (recall Figure 4). Evidently, as an empirical matter, this can change going forward in a way that could not be captured in a starker model.

\footnotetext{
${ }^{23}$ It should be noted though, that even in the absence of sectoral linkages, unequal capital income shares across sectors alone introduce a wedge between relative prices and relative productivities. See Hornstein and Krusell (1996).

${ }^{24}$ Let $p^{y}$ denote the $n \times 1$ vector of prices for sectoral output and $g^{p^{y}}$ the associated long-run growth rate. With multiple sectors and the full set of production linkages, $g^{p^{y}}=(\mathbf{1} \Theta-I) \Xi^{\prime} g^{a}$. See Section 9 of the Technical Appendix for a comparison of the model's implied sectoral trend growth rates in producer prices and the data. Closer to the ISTC literature, Basu et al. (2013) in a similar framework, but imposing that capital and labor are homogeneous and mobile across sectors, obtain an analogous relationship that relates the relative price of capital to a weighted average of all sectoral productivities off the balanced growth path.

${ }^{25}$ The construction of input-output tables and gross product by industry separates intermediation industries' contributions to final demand and their contributions to the direct provision of goods. Therefore, commodity transactions are valued at producers' prices that exclude final purchasers' payments for trade services and transportation costs to obtain the commodities. A useful survey on the treatment of intermediation industries is Yuskavage (2007).
} 


\subsection{Measurement}

While explicitly modeling the production network helps address shortcomings implied by a starker sectoral setup, one challenge with more detailed multisector models is that output is more easily measured in some sectors, for example Durable Goods, than others, such as PBS. In the case of PBS, this matters for at least two reasons. One is that PBS is a large supplier of intermediate inputs to other sectors. The other is that, after the Information sector, PBS is the second largest producer of Intellectual Property Products (IPPs).

Measurement error in PBS then potentially arises in mainly two ways. First, service price deflators that account for quality changes in IPP industries are notoriously difficult to obtain. It is possible, therefore, that our benchmark results incorrectly attribute sources of productivity growth across sectors by understating output in PBS. Second, the distinction between materials and investment goods is sometimes ambiguous, and goods can be misclassified. Over time the BEA has in several instances come to recognize expenditures on goods as investment rather than payments for intermediate inputs. This is the case for example in the comprehensive revisions to the National Income Accounts (NIAs) in 2013 regarding expenditures on R\&D and Entertainment Originals. Our analysis relies on capital flow tables from 1997 to determine the sources of investment goods in different sectors. While these tables already include software as an investment good, they do not line up exactly with the broader IPP definition used in the construction of capital stocks in KLEMS. Our capital requirements matrix, $\Omega$, therefore, likely does not capture all of the investment contributions from PBS, in particular those of its IPP industries.

In the environment we study, the mismeasurement of output growth in one sector, say PBS, will generally affect measured TFP in other sectors. Thus, suppose that sectoral output growth, $g^{y}$, is measured with some error, $\epsilon$, so that measured sectoral output growth is $g^{y, m}=g^{y}+\epsilon$. Then, given production linkages, measured sectoral TFP, $g^{z, m}$, is given by,

$$
g^{z, m}=g^{z}+\Xi^{\prime-1} \epsilon
$$

Therefore, measurement error in any sector's output growth rate, $\epsilon$, is generally reflected in all sectors' measured TFP growth, $g^{z, m}$, through $\Xi^{\prime}{ }^{26}$ In particular, to the degree that output growth in PBS is under measured $\left(\epsilon_{j}<0\right.$ in PBS), so is its TFP growth rate while TFP growth in other sectors tends to be overstated (because the off-diagonal elements of $\Xi^{\prime-1}$ are generally negative). This last expression then allows us to carry out counterfactuals exploring the implications of measurement error in sectoral gross output growth. In particular, removing the measurement error changes GDP growth by

$$
-s^{v \prime}\left(I+\alpha_{d} \Omega^{\prime} \Xi^{\prime}\right) \Xi^{\prime-1} \epsilon=-s^{v \prime} \Xi^{\prime-1} \epsilon-s^{v \prime} \alpha_{d} \Omega^{\prime} \epsilon .
$$

In other words, correcting for downward bias in the measurement of PBS output $\left(\epsilon_{j}<0\right)$, the first term on the right-hand-side of the above expression, $-s^{v \prime} \Xi^{\prime-1} \epsilon$, increases the contributions to GDP growth from

\footnotetext{
${ }^{26}$ See Section 6 of the Technical Appendix for derivations.
} 
Figure 13: Mismeasurement and Misclassification in Professional and Business Services

Construction

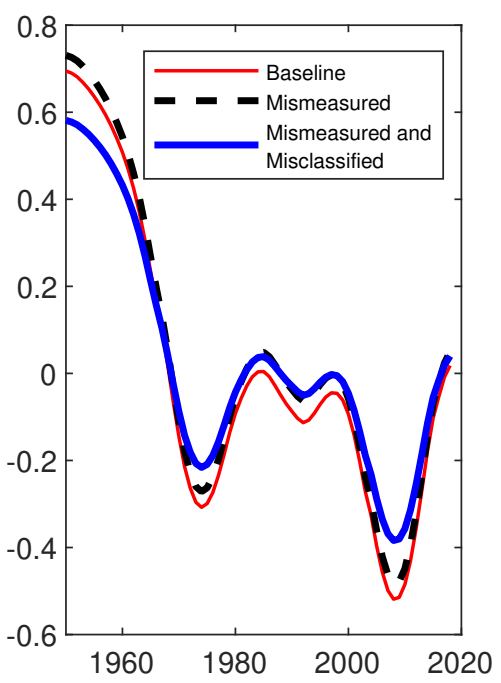

Durable Goods

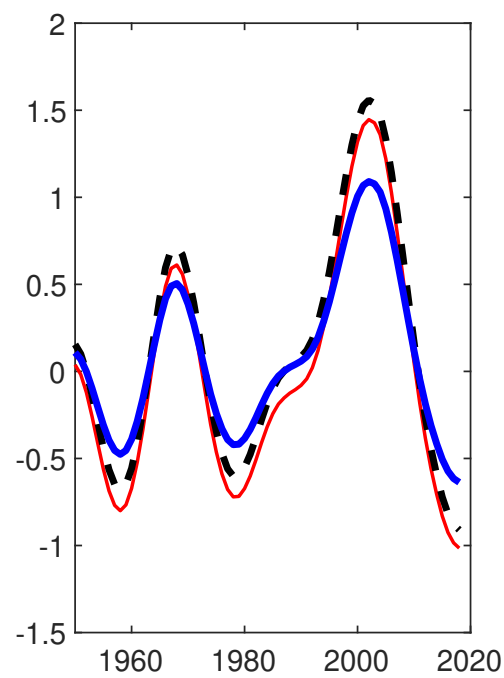

PBS

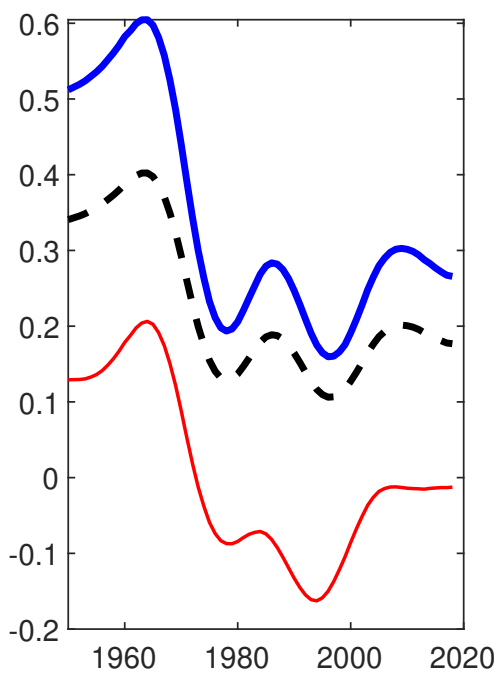

Notes: The red solid lines depict the baseline contributions to trend GDP Growth from the different sectors. The black dashed lines reflect the effects of higher productivity in PBS, implied by the price indices of its IPP industries in the National Income Accounts, on those contributions. The solid blue lines illustrate sectoral contributions to trend GDP growth when, in addition, the capital requirement matrix allows for investment contributions from IPP industries within PBS.

PBS and lowers the contributions from other sectors (TFP growth is now higher in PBS and lower in other sectors). The second term, $-s^{v \prime} \alpha_{d} \Omega^{\prime} \epsilon$, generally increases all other sectors' contributions to GDP growth to the extent that PBS sells some investment goods to these sectors. The net effect of correcting for understated output growth in PBS, therefore, is an increase in its contributions to GDP growth, and either an increase or decrease in the contributions from other sectors.

To explore the role of possible output mismeasurement in PBS, we consider the possibility that price growth in its two IPP related subsectors, namely Computer System Design (BEA Industry Code 5415), and Miscellaneous Professional, Scientific, and Technical Services (BEA Industry Code 5412OP), is overstated in KLEMS. Alternatively, gross output growth in those sectors would be understated. In particular, in a manner comparable to Byrne et al. (2016), we modify observed price measures in the two IPP related subsectors of PBS to be more closely aligned with price measures of IPPs (that cover similar commodities as BEA Industry Codes 5415 and 5412OP) in the National Income Accounts (NIA). The NIA price indices indicate less rapid price growth and, therefore, imply higher productivity (see Section 6 of the Technical Appendix). By using closely related NIA price indices, we interpret this exercise as a reasonable first pass at correcting for suspected bias in the KLEMS prices, or at least providing a sense of robustness with respect to measurement. In this case, the adjustment produces a price index for PBS that increases at a rate that is one percentage point lower than KLEMS prices.

The dashed black line in Figure 13 shows, relative to the contributions to GDP growth originally shown 
in Figure 12, the effects of higher productivity in PBS implied by the more rapidly declining prices of its IPPs in the National Income Accounts. As explained above, higher measured productivity growth in PBS affects all sectors, including Construction and Durable Goods highlighted here. The contributions from PBS to trend GDP growth is noticeably higher both because of the direct effect of higher measured TFP in that sector, through the corresponding element of $-s^{v \prime} \Xi^{\prime-1} \epsilon$ in equation (20), and because the production of other capital goods in PBS benefits from its more productive IPP sectors (and thus lower prices), captured by the corresponding element of $-s^{v \prime} \alpha_{d} \Omega^{\prime} \epsilon$ in (20). In contrast, the quantitative contributions from Construction and Durable Goods to the trend growth rate of GDP do not change appreciably relative to their baseline. On the one hand, measured TFP growth is now smaller in those sectors (i.e., the corresponding elements of $-s^{v} \Xi^{\prime-1} \epsilon$ are negative). On the other hand, those sectors also benefit from employing more productive IPP sectors in PBS in producing their own output $\left(-s^{v \prime} \alpha_{d} \Omega^{\prime} \epsilon>0\right)$.

The other key potential source of mismeasurement in multisector models is the misclassification of goods. Specifically, while the 1997 capital flow tables include software as investment, they do not line up exactly with the broader definition of IPPs used in KLEMS for capital. Thus, they likely miss contributions from PBS to investment stemming from its IPP industries. To explore the implications of this misclassification problem, we separate out the two sectors producing IPPs within PBS, BEA Industry Codes 5415 and $5412 \mathrm{OP}$ defined above, from other PBS industries producing more clearly defined intermediate inputs. ${ }^{27}$ We then construct a modified capital requirement matrix, $\Omega$, that accounts for the possible omission of IPP contributions from PBS to the production of new capital. In particular, as an upper bound for possible mismeasurement in $\Omega$, we reclassify 50 percent of the value of IPPs produced by industries 5415 and $5412 \mathrm{OP}$ in PBS as final investment demand for IPP. This reclassification implies a new capital requirement matrix, $\Omega$, that results in a sectoral multiplier for PBS of 0.36 as compared to our baseline of 0.25 .

The solid blue line in Figure 13 shows the combined effects of the new capital requirement matrix with those correcting for possible bias in KLEMS prices of Intellectual Property Products in PBS. The partial reclassification of Computer System Designs and Miscellaneous Professional, Scientific and Technical Services in PBS from materials to capital raises its sectoral multiplier and lowers those of Construction and Durable Goods. The net effect is that contributions from PBS to trend GDP growth are now higher overall than those of Construction. While the reapportioning of 50 percent of the production value of PBS's main IPPs may be an upper bound on missing contributions from IPP capital in $\Omega$, the exercise nevertheless underscores the importance of classifying goods appropriately. Moreover, this section also highlights the importance of continuing efforts to address challenges associated with the measurement of IPP indices.

\subsection{Production Networks and Capital Accumulation}

In seminal work, Hulten (1978) showed that when different sectors employ inputs produced in multiple other sectors, aggregate TFP is a weighted average of sectoral TFP with weights given by the ratio of sectoral

\footnotetext{
${ }^{27}$ These are Legal Services, Management of Companies and Enterprises, Administrative and Support Services, and Waste Management and Remediation Services.
} 
gross output to GDP, or Domar weights. This result hinges in part on interpreting TFP as scaling gross output. When TFP is instead interpreted as scaling value added as we do here, the relevant weights become value added shares in GDP. ${ }^{28}$ Building on Long and Plosser (1983), a number of papers over the last decade have studied the different ways in which sectoral productivity changes influence aggregate value added.

Acemoglu et al. (2012) note that in a static multi-sector environment abstracting from the production of capital, the same sectoral value added shares also capture the effects of sectoral productivity changes on GDP. They interpret this observation, therefore, in terms of Hulten (1978)'s work on aggregation and refer to the vector of value-added shares as the influence vector. They show that when some sectors serve as hubs in the production network, the distribution of these shares is such that sectoral shocks do not generally cancel out in aggregation. These insights are used in Gabaix (2011) to highlight the importance of shocks to large firms for aggregate variations. Baqaee and Farhi (2019) then explore in a similar environment the role of non-linearities in production for generating GDP effects from sectoral shocks that go beyond what they refer to as Hulten's theorem.

Our work recognizes that a key aspect of an economy's production network arises through sectoral linkages in the production of investment goods in addition to those in materials. The presence of capital, in particular, means that the effects of sectoral changes on GDP reflect the interactions between sectoral linkages and the dynamics of capital accumulation. These features then amplify the aggregate effects of disturbances in different sectors beyond their value added shares. Moreover, they do so under otherwise standard neoclassical assumptions, log-linear technologies and competitive input and product markets. Importantly, unlike the aforementioned papers on production networks, sectoral multipliers here apply to the effects of changes in sectoral input growth on GDP growth, $\partial \Delta \ln V / \partial \Delta \ln A$, rather than levels, $\partial \ln V / \partial \ln A$. This complements the empirical macroeconomics literature's emphasis on the characterization and behavior of growth rates, including at different frequencies, rather than levels. In this case, the new formulas we derive make it possible to explore empirically the secular decline in GDP growth as highlighted in Figure $9 .^{29}$

Beyond our focus on long-run growth, our work highlights the importance of capital accumulation within the production network. Because the investment network plays a key role in amplifying the aggregate effects of sectoral changes, it is reasonable to conjecture that other features related to investment or other sources of dynamics could also play a role. While we allow for sectoral technologies that differ in their input shares, features such as time-to-build, investment adjustment costs, or the cost of holding investment

\footnotetext{
${ }^{28}$ These results are evidently related. When sectoral TFP, $z_{j}$, is measured as scaling value added, $\widetilde{z}_{j, t}=z_{j, t}^{\gamma_{j}}$ becomes the relevant scalar for sectoral gross output, where $\gamma_{j}$ is $j$ 's value added share in gross output, $\frac{p_{j}^{v} v_{j}}{p_{j}^{y} y_{j}}$. In Hulten $(1978), \frac{\partial \ln Z_{t}}{\partial \ln \tilde{z}_{j, t}}=\mathscr{D}_{j}$, where $\mathscr{D}_{j}$ is sector $j$ 's Domar weight or ratio of gross output to GDP, $\frac{p_{j}^{y} y_{j}}{V}$. It immediately follows from the definition of $\widetilde{z}_{j}$ that $\frac{\partial \ln Z_{t}}{\partial \ln z_{j, t}}=\gamma_{j} \mathscr{D}_{j}$, where $\gamma_{j} \mathscr{D}_{j}$ is then simply sector $j$ 's value added share in GDP, $s_{j}^{v}$.

${ }^{29}$ Section 5 of the Technical Appendix shows that the findings and insights in Acemoglu et al. (2012) and subsequent work remain nested in a static version of our economic environment without capital and where the focus is on levels rather than growth rates. However, it also shows that this 'levels' result changes somewhat in the steady state of a dynamic economy with capital. In particular, the effect of a productivity change in a sector on the level of GDP is given by its value added share (or Domar weight) scaled by the inverse of the average labor income share.
} 
goods in inventories likely differ across sectors. Aside from affecting the long-run amplification mechanisms highlighted here, these features likely also help shape how sectoral disturbances play out at business cycle or medium run frequencies. Therefore, more accurately modeling the technologies used in different sectors, and how these technologies affect dynamics at different frequencies, is an important next step.

\section{Concluding Remarks}

In this paper, we study how trends in TFP and labor growth across major U.S production sectors have helped shape the secular behavior of GDP growth. We find that sectoral trends in TFP and labor growth have generally decreased across a majority of sectors since 1950. Common trends in sectoral TFP growth contributed around $1 / 3$ of the secular decline in aggregate TFP growth. Common trends in sectoral labor growth contributed about $2 / 3$ of the secular decline in aggregate labor growth.

We embed these findings into a dynamic multi-sector framework in which materials and capital used by different sectors are produced by other sectors. These production linkages along with capital accumulation mean that changes in the growth rate of labor or TFP in one sector affect not only its own value added growth but also that of all other sectors. In particular, capital induces network effects that amplify the repercussions of sector-specific sources of growth on the aggregate economy and that we summarize in terms of sectoral multipliers. Quantitatively, these multipliers scale up the influence of some sectors by multiple times their value added share in the economy.

Ultimately, we find that sector-specific factors in TFP and labor growth historically explain $3 / 4$ of low frequency variations in U.S. GDP growth, leaving common or aggregate factors to explain only $1 / 4$ of these variations. Changing sectoral trends in the last 7 decades, translated through the economy's production network, have on net lowered trend GDP growth by close to 3 percentage points. The Construction and Durable Goods sectors, more than any other sector, stand out for their contribution to the trend decline in GDP growth over the post-war period, though other sectors with large multipliers, such as Professional and Business Services, could also have an outsize influence on the aggregate economy going forward. Remarkably, no sector has contributed any steady or significant increase to the trend growth rate of GDP in the last 70 years. 


\section{References}

Acemoglu, D., V. M. Carvalho, A. Ozdaglar, and A. Tahbaz-Salehi (2012). The Network Origins of Aggregate Fluctuations. Econometrica 80(5), 1977-2016.

Antolin-Diaz, J., T. Drechsel, and I. Petrella (2017). Tracking the Slowdown in Long-Run GDP Growth. The Review of Economics and Statistics 99(2), 343-356.

Atalay, E. (2017). How Important Are Sectoral Shocks? American Economic Journal: Macroeconomics 9(4), $254-280$.

Baqaee, D. R. and E. Farhi (2018). The Microeconomic Foundations of Aggregate Production Functions. Technical report, NBER Working Paper 25293.

Baqaee, D. R. and E. Farhi (2019). The Macroeconomic Impact of Microeconomic Shocks: Beyond Hulten's Theorem. Econometrica 87(4), 1155-1203.

Basu, S. and J. Fernald (2001). Why Is Productivity Procyclical? Why Do We Care? In New Developments in Productivity Analysis, NBER Chapters, pp. 225-302. National Bureau of Economic Research, Inc.

Basu, S. and J. G. Fernald (1997). Returns to Scale in U.S. Production: Estimates and Implications. Journal of Political Economy 105(2), 249-283.

Basu, S., J. G. Fernald, J. Fisher, and M. S. Kimball (2013). Sector-Specific Technical Change. Mimeo.

Basu, S., J. G. Fernald, N. Oulton, and S. Srinivasan (2004). The Case of the Missing Productivity Growth, or Does Information Technology Explain Why Productivity Accelerated in the United States But Not in the United Kingdom? In NBER Macroeconomics Annual 2003, Volume 18, NBER Chapters, pp. 9-82. National Bureau of Economic Research, Inc.

Byrne, D. M., J. G. Fernald, and M. B. Reinsdorf (2016). Does the United States Have a Productivity Slowdown or a Measurement Problem? Brookings Papers on Economic Activity 47(1 (Spring), 109-182.

Cavallo, M. and A. Landry (2010). The Quantitative Role of Capital Goods Imports in US Growth. American Economic Review 100(2), 78-82.

Cette, G., J. Fernald, and B. Mojon (2016). The Pre-Great Recession Slowdown in Productivity. European Economic Review 88(C), 3-20.

Decker, R. A., J. Haltiwanger, R. S. Jarmin, and J. Miranda (2016). Where has All the Skewness Gone? The Decline in High-Growth (Young) Firms in the U.S. European Economic Review 86(C), 4-23.

Duarte, M. and D. Restuccia (2020). Relative Prices and Sectoral Productivity. Journal of the European Economic Association 18(3), 1400-1443. 
Dupor, B. (1999). Aggregation and Irrelevance in Multi-Sector Models. Journal of Monetary Economics 43(2), 391-409.

Fernald, J., R. Hall, J. Stock, and M. Watson (2017). The Disappointing Recovery of Output after 2009. Brookings Papers on Economic Activity 48(1), 1-81.

Fernald, J. G. (2014). Online Appendix to "Productivity and Potential Output Before, During, and After the Great Recession".

Fisher, J. (2006). The Dynamic Effects of Neutral and Investment-Specific Technology Shocks. Journal of Political Economy 114(3), 413-451.

Foerster, A. T., P.-D. G. Sarte, and M. W. Watson (2011). Sectoral versus Aggregate Shocks: A Structural Factor Analysis of Industrial Production. Journal of Political Economy 119(1), 1-38.

Gabaix, X. (2011). The Granular Origins of Aggregate Fluctuations. Econometrica 79(3), 733-772.

Greenwood, J., Z. Hercowitz, and P. Krusell (1997). Long-Run Implications of Investment-Specific Technological Change. American Economic Review 87(3), 342-362.

Herkenhoff, K., L. Ohanian, and E. Prescott (2018). Tarnishing the Golden and Empire States: Land-Use Regulations and the U.S. Economic Slowdown. Journal of Monetary Economics 93, 89 - 109.

Herrendorf, B., R. Rogerson, and A. Valentinyi (2013). Two Perspectives on Preferences and Structural Transformation. American Economic Review 103(7), 2752-89.

Hornstein, A. and P. Krusell (1996). Can technology improvements cause productivity slowdowns? In NBER Macroeconomics Annual 1996, Volume 11, pp. 209-276. National Bureau of Economic Research, Inc.

Horvath, M. (1998). Cyclicality and Sectoral Linkages: Aggregate Fluctuations from Independent Sectoral Shocks. Review of Economic Dynamics 1(4), 781-808.

Horvath, M. (2000). Sectoral Shocks and Aggregate Fluctuations. Journal of Monetary Economics 45(1), 69-106.

Hulten, C. R. (1978). Growth Accounting with Intermediate Inputs. Review of Economic Studies 45(3), $511-518$.

Jorgenson, D. W., F. M. Gollop, and B. M. Fraumeni (1987). Productivity and U.S. economic growth. Harvard Economic Studies, vol. 159.

Justiniano, A., G. Primiceri, and A. Tambalotti (2011). Investment Shocks and the Relative Price of Investment. Review of Economic Dynamics 14(1), 101-121. 
Justiniano, A., G. E. Primiceri, and A. Tambalotti (2010). Investment Shocks and Business Cycles. Journal of Monetary Economics 57(2), 132-145.

Long, J. B. and C. I. Plosser (1983). Real Business Cycles. Journal of Political Economy 91(1), 39-69.

Miranda-Pinto, J. (2019). Production Network Structure, Service Share, and Aggregate Volatility. Working Paper, University of Queensland 170(C), 152-156.

Müller, U. K., J. H. Stock, and M. W. Watson (2020). An Econometric Model of International Long-Run Growth Dynamics for Long-Horizon Forecasting. Review of Economics and Statistics, forthcoming.

Müller, U. K. and M. W. Watson (2008). Testing Models of Low-Frequency Variability. Econometrica 76, 979-1016.

Müller, U. K. and M. W. Watson (2016). Measuring Uncertainty about Long-Run Predictions. Review of Economic Studies 83, 1711-1740.

Müller, U. K. and M. W. Watson (2018). Long-Run Covariability. Econometrica 86(3), 775-804.

Müller, U. K. and M. W. Watson (2020). Low-Frequency Analysis of Economic Time Series, in preparation. In Handbook of Econometrics. Elsevier.

Ngai, L. R. and C. A. Pissarides (2007). Structural Change in a Multisector Model of Growth. American Economic Review 97(1), 429-443.

Ngai, L. R. and R. M. Samaniego (2009). Mapping prices into productivity in multisector growth models. Journal of Economic Growth 14, 183- 204.

vom Lehn, C. and T. Winberry (2022). The Investment Network, Sectoral Comovement, and the Changing U.S. Business Cycle. Quarterly Journal of Economics 387(1), 387 - 433.

Yuskavage, R. E. (2007). Distributive Services in the U.S. Economic Accounts. Technical report, Bureau of Economic Analysis. 